\title{
VALIDATION OF AN IN VITRO 3D BONE CULTURE MODEL WITH PERFUSED AND MECHANICALLY STRESSED CERAMIC SCAFFOLD
}

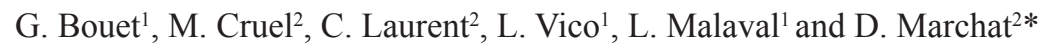 \\ ${ }^{1}$ INSERM U1059, Laboratoire de Biologie Intégrative du Tissu Osseux, University of Lyon, \\ Saint-Etienne, 42023, France \\ ${ }^{2}$ Ecole Nationale Supérieure des Mines, CIS-EMSE, CNRS:UMR 5307, \\ F-42023 158 cours Fauriel Saint-Etienne cedex 2, France
}

\begin{abstract}
An engineered three dimensional (3D) in vitro cell culture system was designed with the goal of inducing and controlling in vitro osteogenesis in a reproducible manner under conditions more similar to the in vivo bone microenvironment than traditional two-dimensional (2D) models. This bioreactor allows efficient mechanical loading and perfusion of an original cubic calcium phosphate bioceramic of highly controlled composition and structure. This bioceramic comprises an internal portion containing homogeneously interconnected macropores surrounded by a dense layer, which minimises fluid flow bypass around the scaffold. This dense and flat layer permits the application of a homogeneous loading on the bioceramic while also enhancing its mechanical strength. Numerical modelling of constraints shows that the system provides direct mechanical stimulation of cells within the scaffold. Experimental results establish that under perfusion at a steady flow of $2 \mu \mathrm{L} / \mathrm{min}$, corresponding to $3 \leq$ Medium velocity $\leq 23 \mu \mathrm{m} / \mathrm{s}$, mouse calvarial cells grow and differentiate as osteoblasts in a reproducible manner, and lay down a mineralised matrix. Moreover, cells respond to mechanical loading by increasing C-fos expression, which demonstrates the effective mechanical stimulation of the culture within the scaffold. In summary, we provide a "proof-of-concept" for osteoblastic cell culture in a controlled 3D culture system under perfusion and mechanical loading. This model will be a tool to analyse bone cell functions in vivo, and will provide a bench testing system for the clinical assessment of bioactive bone-targeting molecules under load.
\end{abstract}

Keywords: Bone tissue engineering, perfusion bioreactor, cell culture, scaffold, calcium phosphates, bioceramic, in vitro.

\author{
*Address for correspondence: \\ David Marchat \\ Center for Biomedical and Healthcare Engineering \\ Ecole Nationale Supérieure des Mines \\ CIS-EMSE, CNRS: UMR 5307 \\ Saint-Etienne, France
}

Telephone number: +33477499701

Fax number: +33477499694

E-mail: marchat@emse.fr

\section{Introduction}

The applications of tissue engineering are no longer restricted to the development of artificial living tissues as manufactured products, but extend beyond therapeutic implants towards the creation of in vitro physiological models of living tissues. Cells in vivo reside in a complex three-dimensional (3D) micro-environment, consisting of several cell types producing extracellular matrix (ECM) and signalling molecules which are subjected (in most tissues, including bone) to mechanical stimuli which determine important aspects of physiology. However, most of our knowledge about cell physiology comes from in vitro two-dimensional (2D) experiments on cell monolayers. Although these culture conditions are drastically simplified and hardly reproduce the typical bone environment in the organ/organism, in which (bone) cells develop in a 3D structure subjected to mechanical stimulation (Elsdale and Bard, 1972).

New generation systems, based on tissue-engineering principles, endeavour to reproduce the environment of the cells within a living organism. Their goal is to provide a robust spatial and temporal control of biophysical, biochemical and mechanical microenvironmental cues (Abousleiman and Sikavitsas, 2006; Burdick and VunjakNovakovic, 2009; Lutolf et al., 2009; Owen and Shoichet, 2010; Schmeichel and Bissell, 2003), as well as monitoring cellular organisation and responses. In order to achieve success in such experimental models, many parameters must be tightly controlled in the culture system (e.g. cell seeding, matrix deposition and mineralisation) and its supporting environment (e.g. nutrient supply, waste removal), which necessitates optimisation of the scaffold and the bioreactor (Bouet et al., 2015b).

The purpose of a scaffold is to provide a $3 \mathrm{D}$ environment for bone cells. To achieve this goal, scaffolds should exhibit several properties. Phase and chemical composition as well as surface chemistry are key parameters directly affecting cellular activities, such as cell attachment, proliferation and differentiation towards the desired phenotype (Anselme, 2011; Boyan et al., 1996; Rawsterne et al., 2007). Additionally, scaffold architecture should allow controlled and homogeneous cell seeding (Abousleiman and Sikavitsas, 2006; Melchels et al., 2010; Salerno et al., 2010), cellular responses (Salerno et al., 2010), mass-transport (Grayson et al., 2012) and possess appropriate mechanical properties (Pecqueux et al., 2010) throughout the experiment. The architecture influences directly (e.g. nutrient accessibility) or indirectly (e.g. adsorption of proteins, local shear stresses) the cellular fate. Optimisation of the mechanical properties for a scaffold is 
important to support perfusion, and mechanical stimulation of the culture (e.g. compressive strength). Therefore, we decided to work with synthetic calcium phosphates $(\mathrm{CaP})$ macroporous ceramics which present most of the qualities required for in vitro bone applications, such as controllable chemistry and architecture, biocompatibility, tuneable biodegradability, osteoconductivity, stiffness similar to bone, and adequate chemical surface functional groups (Bose et al., 2013; Bouet et al., 2015b; Shepherd and Best, 2011; Shepherd et al., 2012). The brittle nature of these ceramics can be partly compensated by architectural optimisation (Bouet et al., 2015b).

Among existing tools, perfusion-based bioreactors represent the most efficient culture system to provide uniform nutrient transport, waste elimination as well as cell distribution, growth and osteoblastic differentiation in the interior of the scaffold (Goldstein et al., 2001; Szpalski et al., 2013). Perfusion also permits mechanical stimulation of the cells by means of shear stress (for a review see McCoy and O'Brien, 2010). These bioreactors can be improved with the addition of a compression system dissociated from or combined with perfusion (Liu et al., 2012), which is particularly useful and relevant in bone cell studies (e.g. analysis of mechanotransduction (Sittichockechaiwut et al., 2009). Few bioreactors are designed to both perfuse and apply dynamic compressive strain-like compression on the scaffold. Such systems were developed and marketed by Bose ${ }^{\circledR}$ (Cartmell et al., 2011) and Zetos ${ }^{\circledR}$ (Davies et al., 2006), or are more artisanal (Bolgen et al., 2008; Jagodzinski et al., 2008). Regarding both commercial systems, they were initially developed for the culture of natural tissues (e.g. bone, cartilage), rather than for manufactured scaffolds, and their technical properties/specifications (e.g. chamber $v s$. scaffold geometry allowing bypass, range of mechanical stimulations) were not fully adapted to the stimulation of $\mathrm{CaP}$ macroporous bioceramics. This last observation also applies to artisanal systems which are adapted for non-load bearing bone studies using cryogels (Bolgen et al., 2008) or bovine acellular matrix (Jagodzinski et al., 2008).

The aim of this study was thus to develop and validate the combination of a bioceramic scaffold and a perfusion bioreactor allowing mechanical loading in order to improve existing 3D culture systems. This 3D culture system should allow control and study of osteoblastic differentiation in a physiologically-relevant in vitro model. To achieve this goal, the culture system should ideally provide homogeneous and controlled fluid flow perfusion (i.e. flow conditions) as well as accurate and controlled mechanical stimulations within the scaffold.

\section{Material and Methods}

\section{Design of scaffolds and perfusion bioreactor system}

In order to uniformly compress the entire scaffold surface, we decided to work with a mechanical loading applied perpendicularly to the fluid flow. The dense flat surfaces of the cubic scaffold, placed into a close-fitting slot (Height 5.0-5.25 mm $\times$ Depth $5.25 \mathrm{~mm} \times$ Width $5.25 \mathrm{~mm}$ ) in the culture chamber, are in contact on one side with the mobile piston delivering the compressive stress (i.e. vertical mechanical loading), and on the opposite side with the counter-piston (Fig. 1A). Sealing of the mobile loading piston is ensured by polytetrafluoroethylene (PTFE) O-rings $(\varnothing 10 \times 1.5 \mathrm{~mm}$, Eynard Robin, France). On both sides of the chamber lateral windows, sealed by O-rings, allow to check scaffold right position, absence of bubble, etc. (Fig. 1B).

In an effort to improve the mechanical properties of the bioceramic, which needs to resist high and cyclic mechanical loading, the non-perfused surfaces (parallel and perpendicular to the compressive stress axis) have been consolidated with an outer supporting dense layer. One of the challenges was to ensure adequate parallelism between the flat surfaces of the piston, which delivers the compressive stress, and of the scaffold. In order to achieve homogeneous scaffold loading, the compressive stress has to be delivered on a flat and smooth surface in full contact with a flat piston surface. Moreover, the dense layer surrounding the porous scaffold and parallel to the direction of perfusion, was also expected to avoid or limit fluid bypass around the scaffold, and thus control the flow experienced by the cells within the scaffold.

The major components of our bioreactor culture system (Fig. 1A, B, C) are a newly developed steel culture chamber connected to a commercial peristaltic pump (IPC-N, Ismatec, Glattbrugg, Switzerland) using 2-stop tubing (Masterflex, ID $=0.48 \mathrm{~mm}$ Beligneux, France). During experiments, both are placed in an incubator at $37^{\circ} \mathrm{C}, 5 \%$ $\mathrm{CO}_{2}$, in a dry atmosphere (Fig. 1C). As culture medium reservoir, a medical fluid infuser (Codan, Vallauris, France) was modified by piercing in sterile conditions a lateral port, plugged by a $22 \mu \mathrm{m}$ sterile syringe filter (Pall, Ann Arbor, MI, USA). This allows both medium change and $\mathrm{CO}_{2}$ equilibration (Fig. 1B). The peristaltic pump was placed after the culture chamber and before the waste collector (Fig. 1B, C). All elements (reservoir, chamber, pump and waste collector) were connected by Tygon oxygen-tight tubing (Masterflex, Beligneux, France). Up to 12 perfused chambers can be run in parallel (Fig. 1C). Chambers and fluid circuits are sterilised by autoclaving $\left(121{ }^{\circ} \mathrm{C}\right.$ for $20 \mathrm{~min}$ ) before use.

During the culture, oxygen $\left(\mathrm{O}_{2}\right)$ levels were measured at the inlet and outlet of the bioreactor every $10 \mathrm{~min}$ for $5 \mathrm{~h} / \mathrm{d}$ (i.e. 30 measurements/d) from day 0 to day 21 . $\mathrm{O}_{2}$ measurements were performed using a flow-through oxygen mini-sensor (FTC, PreSens, Regensburg, Germany) based on the quenching of luminescence by $\mathrm{O}_{2}$. This system does not consume $\mathrm{O}_{2}$ and is independent of the flow rate. The sensor is connected by optical fibres to a transmitter device (Fibox-3, PreSens) linked to a computer. Two FTC sensors were incorporated into the fluid circuit, respectively $10 \mathrm{~mm}$ from the inlet and the outlet of the chamber. The temperature of the chamber was monitored with a temperature sensor (Pt 1000, PreSens) also connected to the transmitter.

\section{Mechanical loading}

Our original culture chamber was developed to be compatible with the Zetos ${ }^{\circledR}$ compression device (David et al., 2008; Davies et al., 2006; Dumas et al., 2009) which 

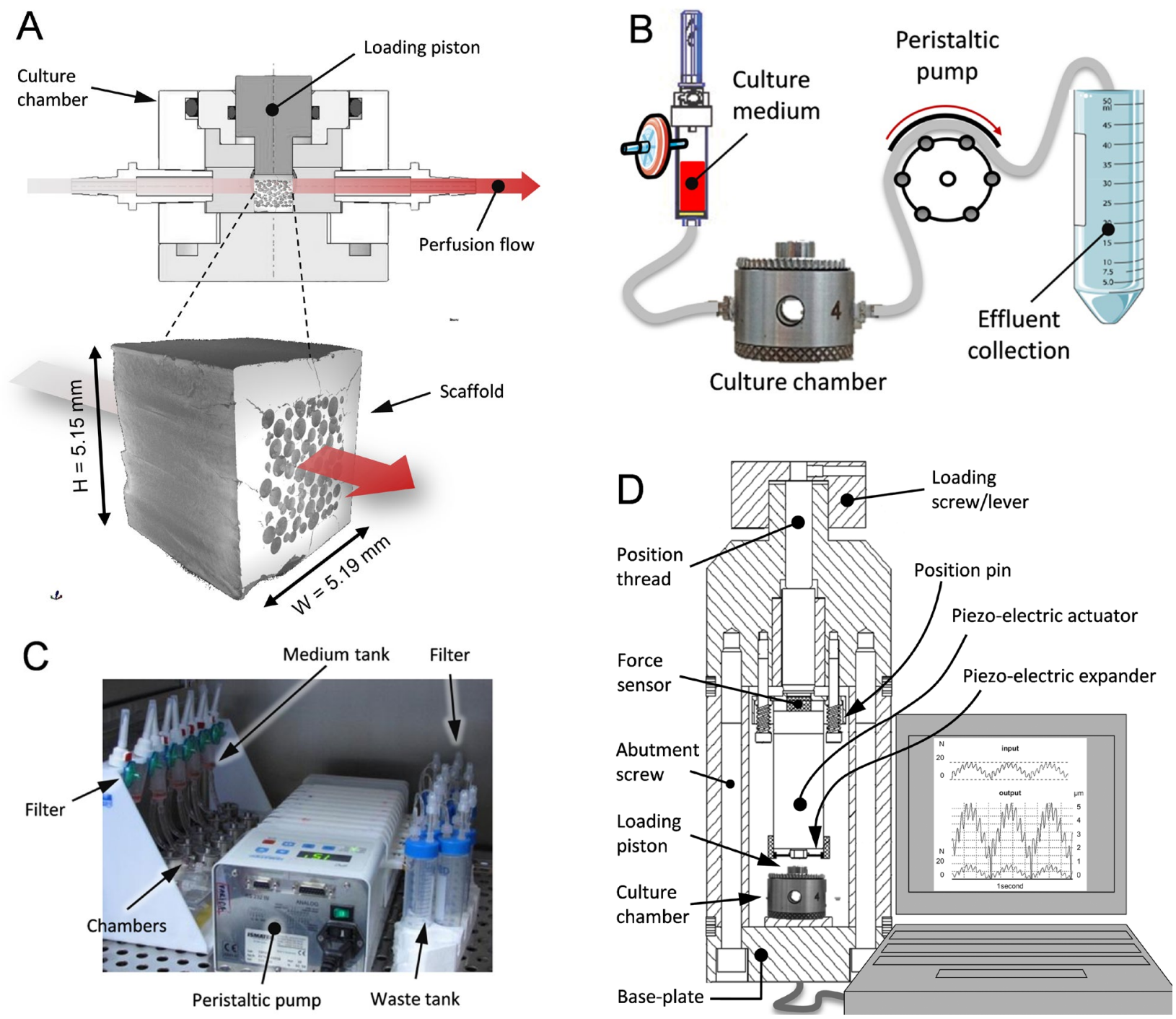

Fig. 1. 3D dynamic culture system. (A) Sectional view of the culture chamber showing the mobile piston on top, ensuring mechanical loading perpendicular to the direction of the perfusion flow (red arrow), and the scaffold ( $\mu \mathrm{CT}$ image) inside its compartment. Flowchart (B) and picture $(\mathbf{C})$ of the bioreactor system, encompassing the culture chamber, a medium reservoir with filter, tubing, peristaltic pump and effluent collector. (D) Sectional view of the Zetos ${ }^{\circledR}$ loading device: the culture chamber is positioned inside the device under a piezo-electric actuator linked to a built-in strain gauge sensor measuring the actuator's expansion. A loading screw is used to apply a mechanical preload on the scaffold. The graph on the right illustrates the output signal, expressed in deformation $(\mu \mathrm{m})$ and in Force $(\mathrm{N})$ which is used in the mechanical strain tests.

can exert cyclic compression on a mobile piston through a piezo-electric actuator controlled by a computer program (Fig. 1D). A complete description of the device is given in Jones et al. (Jones et al., 2003). In our experiments, the scaffolds were subject to a composite mechanical signal pattern previously used by Dumas et al. (Dumas et al., 2009). This signal is a sinusoidal waveform at $3 \mathrm{~Hz}$ frequency with an amplitude of $4 \mu \mathrm{m}$, to which are superimposed $25 \mathrm{~Hz}$ vibrations of $<1.5 \mu \mathrm{m}$ amplitude (Fig. 1D). This combination of compression strain regimens was found to increase the production of major matrix components of the bone tissue by the osteoblastic cell line, MG-63, grown in ceramic scaffolds (Dumas et al., 2009). After $5 \mathrm{~d}$ of culture, the scaffolds were subjected, one by one, to a unique episode of 15 min compressive cyclic loading. To ensure a proper contact between the mobile piston and the scaffold, a preloading of $1 \mu \mathrm{m}$ of amplitude was performed before stimulation. For mechanical stimulation, the chambers were isolated from the perfusion circuit and moved to the Zetos ${ }^{\circledR}$ device located in a separate incubator. They were replaced in the perfusion system immediately after the stimulation bout. Control scaffolds were processed in the same manner as the stimulated ones (i.e. same incubation time, same chamber handling steps) but did not undergo mechanical loading.

\section{Synthesis of powders}

Calcium hydroxyapatite $\mathrm{Ca}_{10}\left(\mathrm{PO}_{4}\right)_{6}(\mathrm{OH})_{2}(\mathrm{HA})$ and apatitic tricalcium phosphate $\mathrm{Ca}_{9}\left(\mathrm{HPO}_{4}\right)\left(\mathrm{PO}_{4}\right)_{5}(\mathrm{OH})(\mathrm{Ap}-\mathrm{TCP})$ powders were prepared by a standard aqueous precipitation 
Table 1. Powder synthesis parameters.

\begin{tabular}{|c|c|c|c|c|c|c|c|}
\hline Powder & $\begin{array}{c}\left(\mathrm{n}_{C a} / n_{P}\right) \\
\text { reagents }\end{array}$ & $\mathrm{pH}$ & $T$ & {$[\mathrm{Ca}]$} & {$[\mathrm{P}]$} & $\begin{array}{c}\text { Adding } \\
\text { flow }\end{array}$ & $\mathrm{t}_{\text {maturation }}$ \\
\hline & - & - & $/{ }^{\circ} \mathrm{C}$ & $/ \mathrm{mol}^{-1}$ & $/ \mathrm{mol}^{-1}$ & $/ \mathrm{mL}^{-m_{n}}{ }^{-1}$ & $/ \mathrm{h}$ \\
\hline HA & 1.667 & 8.0 & 65 & 2.329 & 1.397 & 316 & 17 \\
\hline Ap-TCP & 1.500 & 7.0 & 35 & 2.117 & 1.422 & 316 & 17 \\
\hline
\end{tabular}

method using diammonium phosphate $\left(\left(\mathrm{NH}_{4}\right)_{2} \mathrm{HPO}_{4}, 99 \%\right.$ pure, Merck, Germany) and calcium nitrate tetrahydrate salts $\left(\mathrm{Ca}\left(\mathrm{NO}_{3}\right)_{2}-4 \mathrm{H}_{2} \mathrm{O}, 99 \%\right.$ pure, Merck, Germany). After dissolution of these salts in pure water $(<10 \mu \mathrm{S} / \mathrm{m})$, the phosphate solution was injected into the calcium solution using a peristaltic pump (Heidolph, Germany). The $\mathrm{pH}$ of the suspension was adjusted by the addition of $28 \%$ ammonia solution (Merck, Germany) by means of a dosing pump (GALa 0420 TTT, Prominent, Strasbourg, France), and the temperature was regulated automatically with an external T-probe. The suspension was continuously stirred at $300 \mathrm{rpm}$. After complete introduction of the phosphate solution, the suspension was matured for $17 \mathrm{~h}$, and then filtered using a filter press (Latham International, England). Precipitation and maturation steps were performed under a flow of argon (4.8, Linde, $0.4 \mathrm{~L} / \mathrm{min}$ ) to prevent any excessive carbonation of the precipitate. Synthesis parameters are listed in Table 1. Finally, the precipitate was dried $\left(70^{\circ} \mathrm{C}\right.$ for $\left.3 \mathrm{~h}\right)$ then calcined at $400{ }^{\circ} \mathrm{C}$ for $2 \mathrm{~h}$ before being fine crushed to a 1 to $10 \mu \mathrm{m}$ range (Alpine, AF100, Germany). Pure $\beta$-TCP formation was complete only after calcination of the Ap-TCP at a temperature over $750{ }^{\circ} \mathrm{C}$.

\section{Scaffold preparation}

The scaffolds were manufactured by impregnating an organic template with a calcium phosphate slurry according to the process of Descamps et al. (Descamps et al., 2008). This allowed for full control of the round shape and diameter of the macro-pores (i.e. pore size larger than $100 \mu \mathrm{m})$, their interconnections, as well as the formation of micro-pores (i.e. pore size smaller than $20 \mu \mathrm{m}$ ). The latter aspect was controlled through the physical properties of the powder (e.g. specific surface area) and the sintering parameters. The macro-scale properties were adjusted through the organic template, which was composed of interconnected polymethylmethacrylate (PMMA) beads (500-700 $\mu \mathrm{m}$ diameter, Lucite Daikon Bead Polymer, The Netherlands) and overlapping was performed by chemiforming, using acetone (99.9\% Sigma-Aldrich, Germany) solution diluted to $75 \%(\mathrm{v} / \mathrm{v})$, and controlled through the macroscopic shrinkage of the template.

These templates were impregnated with a calcium phosphate slurry prepared by blending $63.9 \%$ (w/w) of dried powder for $2 \mathrm{~h}$ at $45 \mathrm{rpm}$ in an alumina jar with alumina beads of $10 \mathrm{~mm}$ diameter (Tosoh, $99.5 \%$, Japan), $35.1 \%(\mathrm{w} / \mathrm{w})$ of pure water and $1.0 \%(\mathrm{w} / \mathrm{w})$ of dispersing agent (Darvan C-N,R. T. Vanderbilt Company Inc, USA). The second step consisted in mixing the suspension with an organic binder (Duramax B-1000, Rohmand Haas, France) at $3.7 \%(\mathrm{w} / \mathrm{w})$ using a propeller stirrer for $1 \mathrm{~h}$.

The dried powder was composed of a mixture of $85 \%$ $(\mathrm{w} / \mathrm{w})$ of $\beta$-TCP powder and $15 \%(\mathrm{w} / \mathrm{w})$ of HA powder.
The same lots of $\beta$-TCP powder and HA powder were used for the entire study. Before mixing, these powders were calcined at $800{ }^{\circ} \mathrm{C}$ for $2 \mathrm{~h}$ and $1 \mathrm{~h} \mathrm{(ramps} 4{ }^{\circ} \mathrm{C} / \mathrm{min}$ ), respectively, in order to achieve specific surface areas of $10.0 \pm 0.2 \mathrm{~m}^{2} / \mathrm{g}$ and $20.5 \pm 0.3 \mathrm{~m}^{2} / \mathrm{g}$. These values were determined on outgassed powders at $150{ }^{\circ} \mathrm{C}$ for $8 \mathrm{~h}$ by means of the Brunauer-Emmett-Teller (BET) 5 points method using $\mathrm{N}_{2}$ adsorption isotherms (Micromeritics ASAP 2010, Germany). These thermal treatments did not change the particle size distribution of the powders, which ranged between 1 and $10 \mu \mathrm{m}$ (data not included).

The green body, obtained after drying overnight at $37^{\circ} \mathrm{C}$, was debinded to eliminate organic components (e.g. binder) as well as the PMMA skeleton (Descamps et al., 2008), then sintered at $1100{ }^{\circ} \mathrm{C}$ for $3 \mathrm{~h}$ (ramps $\left.4{ }^{\circ} \mathrm{C} / \mathrm{min}\right)$ to get the macroporous ceramic. Finally, the ceramics were sterilised at $180^{\circ} \mathrm{C}$ for 30 min with a dry heat steriliser (Poupinel, Binder, Germany).

\section{Scaffold characterisation}

Crystalline phases were identified for powders and crushed scaffolds by means of a $\theta / 2 \theta$ X-ray diffractometer (Siemens D5000, Germany) using $\mathrm{CuK} \alpha$ radiation at $40 \mathrm{kV}$ and $20 \mathrm{~mA}$. X-ray diffraction (XRD) patterns were collected over $2 \theta$ range of $28.4-32.7^{\circ}$ with a step size of $0.02^{\circ}$ and counting time of $21 \mathrm{~s}$ per step. Phase identification was performed by comparison to standard patterns from the International Centre for Diffraction Data - Powder Diffraction Files (ICDD-PDF). The $\mathrm{Ca} / \mathrm{P}$ molar ratio of powders and HA $/ \beta$-TCP scaffolds were determined after calcination at $1000{ }^{\circ} \mathrm{C}$ for $15 \mathrm{~h}$ from quantitative $\mathrm{X}$-ray diffraction analysis according to a standard procedure (Raynaud, 2001).

Fourier Transformed Infrared (FT-IR) measurements were carried out with a HYPERION 2000 Spectrometer (Bruker, Germany). The spectra were recorded on powders and crushed scaffolds over a $450-4000 \mathrm{~cm}^{-1}$ range with a $2 \mathrm{~cm}^{-1}$ resolution and each pattern was an average of 32 successive scans.

Morphometric characterisation of the scaffolds was performed by scanning them with a high-resolution microX-ray computed tomograph $(\mu \mathrm{CT}$, Viva CT40, Scanco Medical, Bassersdorf, Switzerland). Data were acquired at $70 \mathrm{keV}$, with a $10 \mu \mathrm{m}$ cubic resolution. Three-dimensional reconstructions of the porous fraction of the scaffolds were generated using the following parameters: sigma, 0.8 ; support, 1; threshold, 263. The structural parameters of material fractional volume (=1-porosity, in \%) and average separation between the struts (= pore diameter in this 3D configuration, in $\mu \mathrm{m}$ ) were generated from the whole stack of sections using the dedicated Scanco software (version $6.0)$. 
Scaffold porosity was characterised by $\mathrm{Hg}$ porosimetry (Autopore IV, Micromeritics, Germany) and Scanning Electron Microscopy (SEM-FEG, JEOL JSM-6500F, USA). Qualitative SEM images were obtained after gold sputtering $(20 \mathrm{~mA}, 50 \mathrm{~s})$ of the samples for electrical conductance (Quorum Q150R ES, England). Due to the "bottleneck" structure of the macropores, which resulted from the overlapping of spheres (i.e. size-limiting pore interconnections), pore size distribution determined by $\mathrm{Hg}$ porosimetry represented the range of interconnection diameters.

Compression tests were conducted on three representative scaffolds. These tests were run with an Instron mechanical testing machine (single-column model 3342 capacity $500 \mathrm{~N}$, Instron, Norwood, USA) at a speed rate of $0.1 \mathrm{~mm} / \mathrm{min}$. The samples were loaded with an increasing force up to $400 \mathrm{~N}$ and displacements precisely monitored by stereo image correlation. The stress-strain data were obtained by taking into account the initial dimensions of the scaffold. The macroscopic modulus $\mathrm{E}_{\text {macro }}$ was measured from the elastic region of the curve. This value was useful for determining the microscopic mechanical properties of the material for numerical simulations.

\section{Numerical modelling and finite element analysis}

Scaffolds were imaged by a Nanotom ${ }^{\circledR}$ X-ray computed tomography system at $180 \mathrm{KeV}$ with $4 \mu \mathrm{m}$ voxel. Phoenix datos $\mid \mathrm{x}$ (General Electric, Fairfield, USA) and image J softwares were used to generate binarised cross sections for analysis.

The stack was then opened with the 3D visualisation software Avizo $^{\circledR}$ (Mercury Computer Systems, Chelmsford, USA, version Standard 5) and a 3D surface mesh was generated from the binarised images. The quality of this mesh was improved, uncorrected regions removed and the 3D volume meshed with tetrahedron elements. Approximately half of the scaffold, truncated perpendicularly to the fluid flow direction, was meshed and exported for simulations to significantly reduce the calculation time. The mesh generated presented around 570,000 elements. Simulations of the biomaterial mechanical behaviour under compression were performed with a finite element model (Abaqus ${ }^{\circledR}$, Dassault Systèmes, Vélizy-Villacoublay, France, version 6.9-2) and the behaviour of the material was assumed to be homogeneous, linear, isotropic and elastic. A displacement of $2.5 \mu \mathrm{m}$ was imposed on the nodes constituting the upper face of the sample, corresponding to a load of $20 \mathrm{~N}$, while nodes from the bottom face were blocked both in the compression and translation directions. Poisson's ratio $v$ was fixed at 0.3 from previous studies (Shibata et al., 2008) and the elastic modulus $\mathrm{E}_{\text {micro }}$ was defined after a first step of inverse analysis, as described in Van Rietbergen et al. (van Rietbergen et al., 1995). In this approach, the simulation was run with a first guess of the microscopic elastic modulus $\mathrm{E}_{0}$ and the predicted macroscopic elastic modulus $\mathrm{E}_{\mathrm{Comp}}$ could be calculated by simulating the same boundary conditions as in the experiments. Within the linear elastic assumption, the true microscopic elastic modulus $\mathrm{E}_{\text {micro }}$ can then be determined by:

$$
E_{\text {micro }}=\frac{E_{\text {macro }}}{E_{\text {comp }}} * E_{0}
$$

The output of interest was the distribution of strains inside the porous part of the scaffold.

\section{Cell isolation and 3D culture}

Mice (129sv/CD1 mixed background) were bred in the PLEXAN facility of the University of Jean Monnet medical faculty (Saint-Etienne, France) at $23 \pm 2{ }^{\circ} \mathrm{C}$ with a $12 \mathrm{~h}$ light/dark cycle. Mice were fed A03 food (Scientific Animal Food and Engineering, Aury, France) and had free access to tap water. The procedure for the care and euthanasia of the animals was in accordance with the European Community standards on the care and use of laboratory animals (Ministère de l'Agriculture, France, Authorisation 90SV08) and animal handling was approved by the local Animal Care Committee. 6 day-old mice were killed by decapitation; the skull caps (calvaria) were dissected out. The calvaria were isolated, cleaned of contaminating connective tissues, dissected along the sagittal suture and pooled (Bellows et al., 1998). The bone pieces were digested at $37{ }^{\circ} \mathrm{C}$ with $0.4 \%(\mathrm{w} / \mathrm{v})$ of Collagenase type 1 (Sigma, Saint-Louis, MO, USA) in Ham's F-12 Medium (Sigma). The cells extracted during the first 5 min of digestion were discarded and six consecutive digestions, lasting from 5 to $20 \mathrm{~min}$, were performed. The successive populations obtained were first fibroblast like, then progressively enriched in cells of polygonal, more osteoblast like morphology in later digests (Bakker and Klein-Nulend, 2012). The cells were pooled, filtered and plated in T-75 flasks in Minimum Essential Medium Eagle (MEM, Sigma) supplemented with $2 \mathrm{mM}$ L-glutamine (Sigma), $50 \mathrm{U} / \mathrm{mL}$ penicillin (Sigma), $50 \mu \mathrm{g} /$ $\mathrm{mL}$ streptomycin (Sigma), and $10 \%(\mathrm{v} / \mathrm{v})$ foetal calf serum (FCS, Biowest, France), hereafter referred to as "culture medium". These cells display at early cultures times no significant osteoblast marker expression. With the progression of the culture in osteogenic conditions, a subpopulation of osteoprogenitors proliferates and forms after confluence colonies of matrix-laying and mineralising osteoblasts, expressing all markers of this cell type and differentiating further to form matrix-embedded osteocytes (Malaval et al., 1999).

Before seeding, the scaffolds were immersed in culture medium under vacuum for $30 \mathrm{~min}$ to remove air bubbles. Calvarial cells were trypsinised $24 \mathrm{~h}$ after plating and then $1.5 \times 10^{6}$ cells were added to a scaffold in a tightly-sealed $5 \mathrm{~mL}$ vial, gently rotated for $24 \mathrm{~h}$ at $15 \mathrm{rpm}$ and $37^{\circ} \mathrm{C}$.

The seeding efficiency was assessed on images taken with a Zeiss AxioObserver ${ }^{\circledR}$ optical fluorescent video microscope (Zeiss, Le Pecq, France) and acquired with the AxioCam ${ }^{\circledR}$ camera using the AxioVision ${ }^{\circledR}$ software (Zeiss, version 4.8.1.0). Collected scaffolds were cut in the middle with a razor blade (Accu-Edge ${ }^{\circledR}$, Feather safety razor co., Osaka, Japan), parallel to the direction of perfusion and then stained with DAPI. The nuclei of nonapoptotic adherent cells onto the inner pore wall surface of the scaffold were then counted in 15 randomly selected fields per scaffolds ( $n=4$ scaffolds). Cell numbers were normalised to the inner pore wall area by equating the 
imaged surface to a set of half-pores of $380 \mu \mathrm{m}$ average diameter (see results section 3.1); thus $1 \mathrm{~mm}^{2}$ of imaged area amounts to $1.57 \mathrm{~mm}^{2}$ of inner pore wall area, value which was used in the calculation of the plating density. The same method was used to assess cell growth into the pore domain of the scaffolds after 7, 14 and $21 \mathrm{~d}$ of culture.

Seeded scaffolds were collected and inserted into medium-filled chambers. To induce osteogenesis, the perfusion culture medium was supplemented with $50 \mu \mathrm{g} / \mathrm{mL}$ ascorbic acid (Sigma) and $10 \mathrm{mmol} / \mathrm{L}$ betaglycerophosphate (Sigma). 3D cell cultures were performed for 7, 14 or $21 \mathrm{~d}$ and the medium in the tank was changed every 2-3 d.

\section{Macroscopic characterisation of cellular activity}

For immunolabelling, the scaffolds were collected, rinsed in PBS and fixed in $3.7 \%(\mathrm{w} / \mathrm{v}=10 \%$ dilution of the saturated solution) paraformaldehyde (PFA) in PBS, for $15 \mathrm{~min}$ at room temperature (RT). They were then cut in half, further fixed in PFA for 15 min and again extensively washed in PBS. Anti-mouse FN primary rabbit antibody (Sigma, ref. 051M4777) was used to label fibronectin (FN) using Alexa-Fluor ${ }^{\circledR}-488$ conjugated goat anti-rabbit IgG (Invitrogen, Life Technologies, Eugene, OR, USA, ref. A011034) as the secondary label. For collagen type 1 (Coll1 $\alpha 1$ ), an anti-mouse specific rabbit antibody (Abcam, Cambridge, UK, ref. ab292) and an Alexa-Fluor ${ }^{\circledR}-555$ conjugated goat anti-rabbit IgG (Invitrogen, ref. A21428) were used.

All primary antibodies were diluted 1:100 in PBS containing with $10 \%(\mathrm{v} / \mathrm{v})$ goat serum (labelling buffer). Labelling was performed overnight at $4{ }^{\circ} \mathrm{C}$ in a humid chamber. The samples were rinsed with PBS and incubated with a mixture of secondary antibody $(1: 100)$ and 4'6-diamidino-2-phenylindole (DAPI, Chemicon, Temecula, CA, $1 \mu \mathrm{g} / \mathrm{mL}$ ) in labelling buffer for $1.5 \mathrm{~h}$ at room temperature. After rinsing, the scaffolds were observed and images acquired with a video microscope as described above.

To assess osteoblast differentiation after $14 \mathrm{~d}$ of culture, first alkaline phosphatase (ALP) staining was performed on half-scaffolds following the manufacturer's protocol (Alkaline Phosphatase kit, Sigma, Ref. 85L2), then mineralised nodules were stained bright red with an Alizarin Red Solution (2\% in water, $\mathrm{pH}$ 4.1-4.3, 1 min incubation). Half-scaffolds were then washed in distilled water prior to imaging.

Scanning electron microscopy (SEM, JEOL JSM$6500 \mathrm{~F}, \mathrm{USA}$ ) was used to image cells and ECM deposited in scaffolds after $7 \mathrm{~d}$ of culture. After a first rinsing in sodium cacodylate buffer solution (0.1 M, pH 7.4), scaffolds were fixed with $2.5 \%$ glutaraldehyde in the same buffer for $30 \mathrm{~min}$ at $4{ }^{\circ} \mathrm{C}$, then cut in half, incubated $30 \mathrm{~min}$ more in fixative, and finally rinsed twice in buffer. Samples were dehydrated in successive ethanol baths, then immersed in hexamethyldisilazane (HMDS, Sigma) for $30 \mathrm{~s}$ before drying and storage in a desiccator. Prior to imaging, samples were gold coated by the low vacuum sputter coating method (Quorum, Q150R ES, England).

\section{RNA extraction and QRT-PCR}

Frozen scaffolds (in liquid nitrogen) were crushed at $3000 \mathrm{rpm}$ for $15 \mathrm{~s}$ with two stainless steel beads $(0.7 \mathrm{~mm}$, Retsch, Haan, Germany) in a Mikro-Dismembrator S laboratory ball mill (Sartorius, Palaiseau, France) and total RNA isolated by mixing TRI reagent (Sigma) with the powder. Extracts were centrifuged at $10,000 \times g$ for $10 \mathrm{~min}$ at $4{ }^{\circ} \mathrm{C}$ to remove debris and RNA isolated from the supernatants following the manufacturer's protocol. RNA concentration was assessed with the Ribogreen kit (Invitrogen) and its quality was controlled with the Experion automated electrophoresis station (BIO-RAD, Hercules, CA, USA). Samples were stored at $-80{ }^{\circ} \mathrm{C}$ until further analyses. Complementary DNA (cDNA) was synthesised from $1 \mu \mathrm{g}$ of total RNA with the iScriptTM cDNA Synthesis kit (BIO-RAD) for Thermal Cycler (MJ Mini Personal Thermal Cycler, BIO-RAD) according to the manufacturer's instruction.

For QRT-PCR, RNA was reverse-transcribed (iScript cDNA synthesis Kit, Biorad) according to manufacturer's instruction, then $40 \mathrm{ng}$ of the cDNA were amplified using the SYBR Green I dye (Lightcycler faststart DNA master SYBR green I, Roche, Germany). Reactions (CFX96TM, BIO-RAD) were performed in $20 \mu \mathrm{L}$ PCR mixture containing 5X Master Mix (dNTP mixture with dUTP instead of dTTP, MgCl2, SYBR Green I dye, Taq DNA Polymerase, and reaction buffer) and forward and reverse primers $(10 \mu \mathrm{M})$. Primer sequences are displayed in Table 2. Messenger RNA expression levels were normalised to cyclophilin A. An RNA sample from mouse calvaria 2D

Table 2. Primer sequences (5' to 3') used for real-time QRT-PCR.

\begin{tabular}{|l|l|l|c|c|}
\hline Genes & Forward & Reverse & PCR product size (pb) & Source \\
\hline Runx2 & ccgggaatgatgagaactac & tgtctgtgccttcttggttc & 223 & NM_009820.4 \\
\hline OSX & atggcgtcctctctgcttg & aaggtcagcgtatggcttct & 153 & NM_130458.3 \\
\hline Col1 $\alpha 1$ & caccetcaagagectgagtc & ttaggcgcaggaaggtcagc & 374 & NM_007742.3 \\
\hline OPN & cccggtgaaagtgactgattc & atggctttcattggaattgc & 193 & NM_009263.2 \\
\hline ALP & agttactggcgacagcaagc & ggacctgagcgttggtgtta & 244 & NM_007431.2 \\
\hline OCN & ctctgacctcacagatgccaa & ctggtctgatagctcgtcaca & 190 & NM_007541.2 \\
\hline BSP & cggaggagacaacggagaag & gtaagtgtcgccacgaggct & 295 & NM_008318.3 \\
\hline c-fos & cgggtttcaacgccgactac & aaagttggcactagagacggacaga & 170 & NM_010234.2 \\
\hline Cyclophilin A & tacacgccataatggcactg & ccatggcttccacaatgttc & 227 & NM_008907.1 \\
\hline
\end{tabular}

Abbreviations: OSX, osterix; Col1 $\alpha 1$, collagen I $\alpha 1$ chain; OPN, osteopontin; ALP, alkaline phosphatase; OCN, osteocalcin; BSP, bone sialoprotein. 

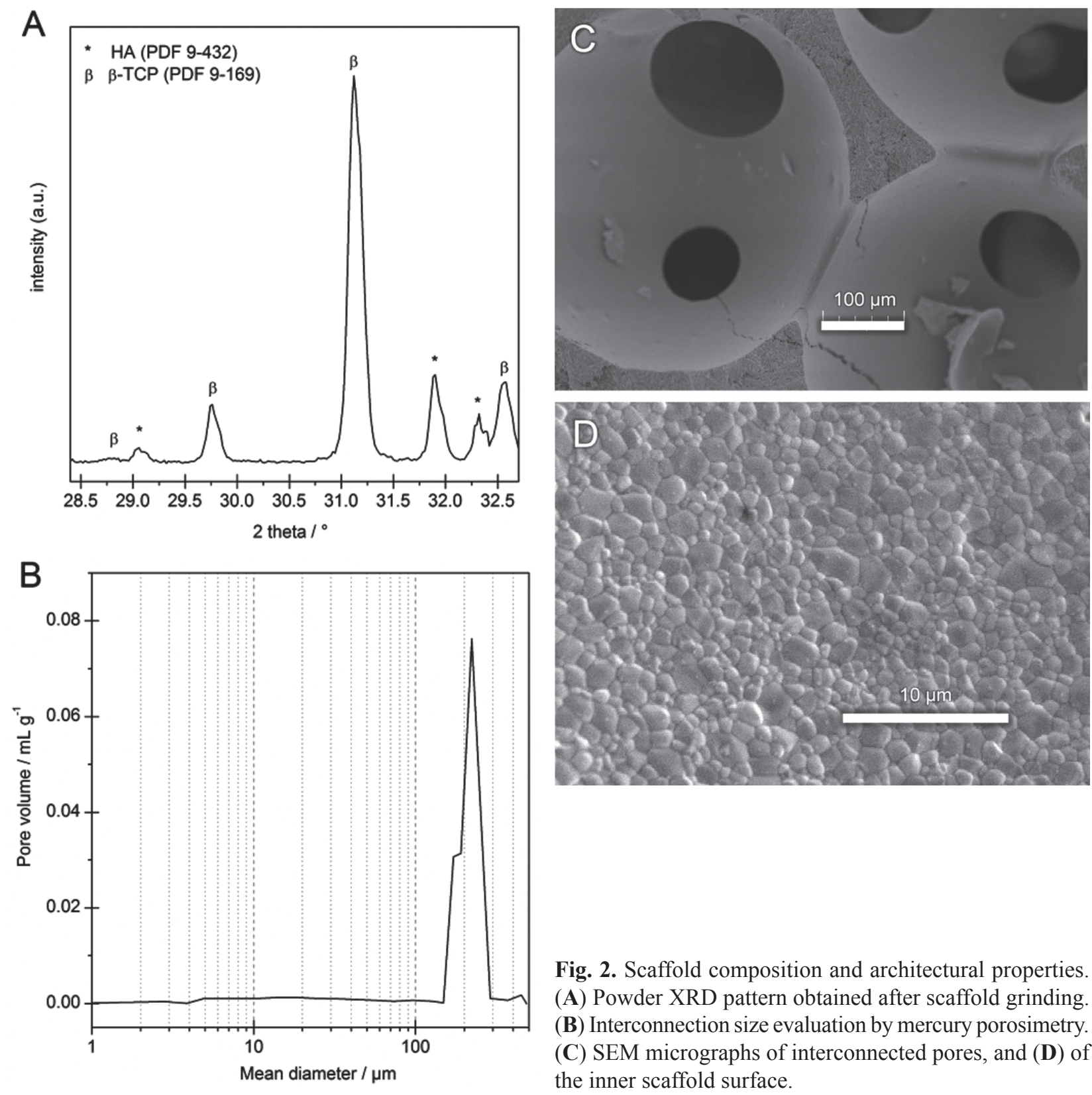

Fig. 2. Scaffold composition and architectural properties. (A) Powder XRD pattern obtained after scaffold grinding. (B) Interconnection size evaluation by mercury porosimetry. (C) SEM micrographs of interconnected pores, and (D) of the inner scaffold surface.

cell cultures was used to build the standard curves from 10-fold dilutions of total RNA.

\section{Statistical analysis}

Data in Fig. 5, 8 and 10 are presented as box-plots, in which the bottom and top box limits mark the first and third quartile, respectively; the horizontal line gives the median and the whiskers the range of the data set. They were assessed with the non-parametric Mann-Whitney U-test, using the STATISTICA ${ }^{\circledR}$ software (version 8.2; StataCorp, College Station, TX). In Fig. 6, data are given as individual measurements and adjusted curves (linear or $4^{\text {th }}$ degree polynomial) with a $95 \%$ confidence interval, as calculated by the Origin ${ }^{\circledR} 8.6$ software. In Fig. 7B, living cells for individual scaffolds are shown as empty dots.

\section{Results}

\section{Scaffold characterisation}

Macroporous scaffolds, produced with pure lots of HA and $\beta$-TCP powder (data not included), exhibited peaks characteristic of HA (PDF 09-432) and TCP (PDF 09-169), as shown in Fig. 2A. No secondary crystalline (XRD) or amorphous phase (IR spectroscopy, data not included) was detected. The percent by weight of the crystalline phases HA and $\beta$-TCP in scaffolds, determined with the standard method of Raynaud et al. (Raynaud et al., 2001), was assessed at $15.6 \pm 0.3 \%$ and $84.4 \pm 0.3 \%$, respectively $(n=6)$. Scaffolds had a cubic geometry H $5.15 \pm 0.05 \times \mathrm{L}$ $4.90 \pm 0.20 \times \mathrm{W} 5.19 \pm 0.08 \mathrm{~mm}(n=40)$, with a $0.9 \mathrm{~mm}$ thick dense portion (hereafter referred to as "cortical part" or "cortex") surrounding the porous internal portion parallel to the direction of perfusion (Fig. 1A). The range 

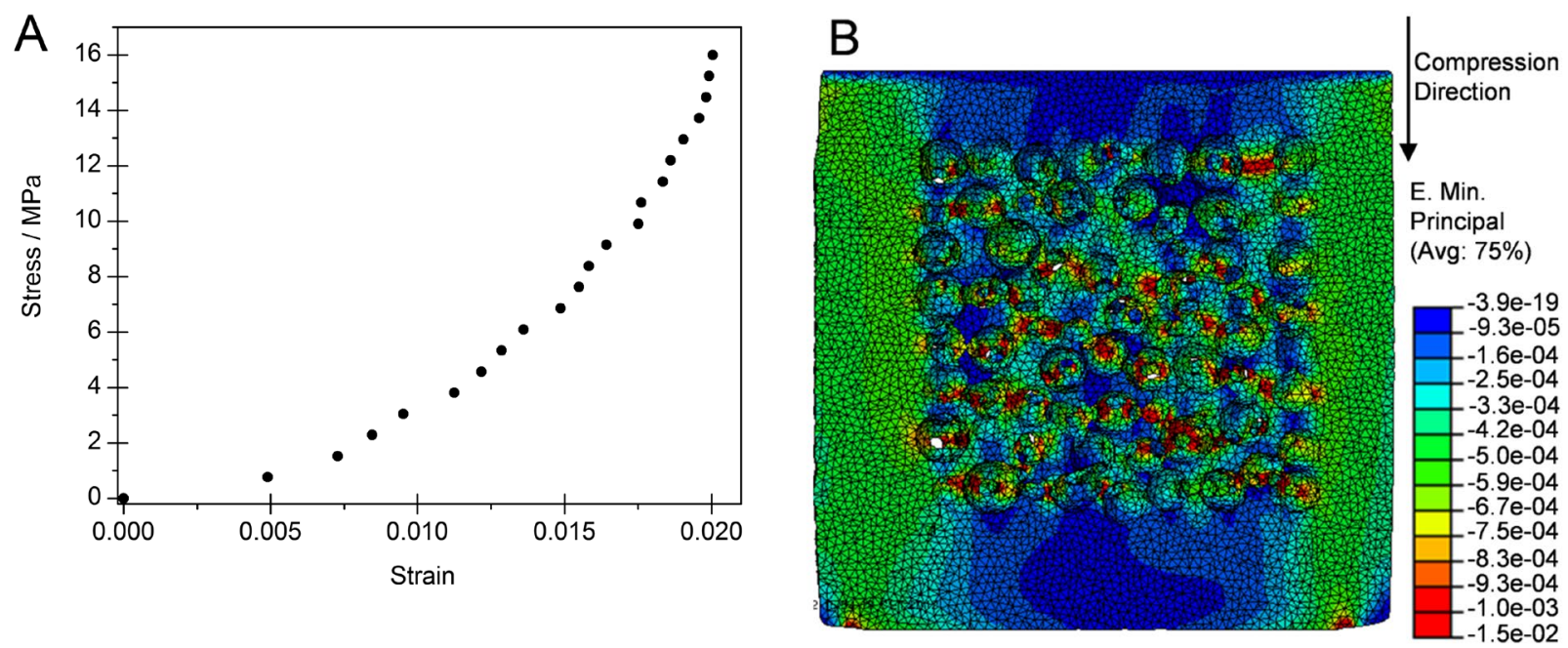

Fig. 3. Scaffold mechanical properties. (A) Stress-strain curve from sample compression testing. (B) Distribution of compressive strains inside the scaffold with an applied force of 20 N. (C) Detail view of a high strain zone between pores. The coloured scale shows strain levels within the scaffold from the lowest (blue) to the highest (red) values.

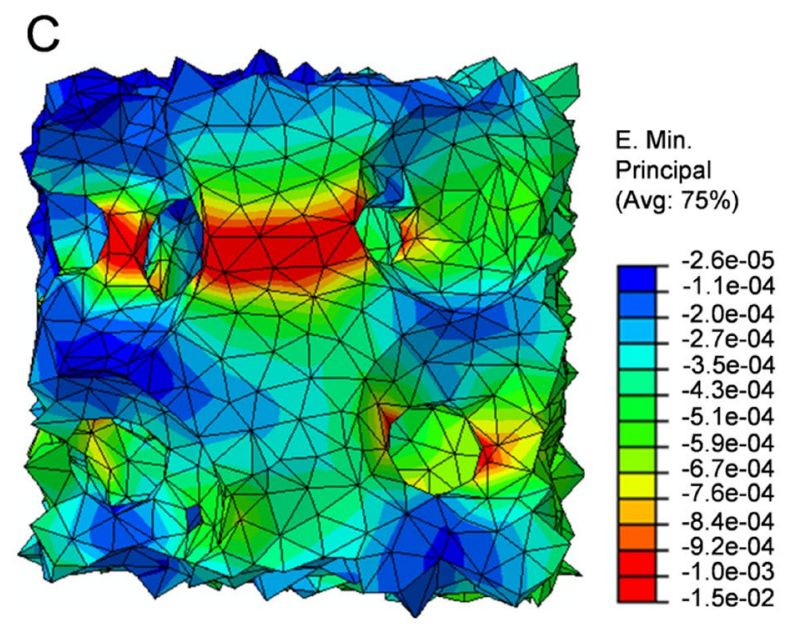

of $\mathrm{H}$ and $\mathrm{W}$ dimensions of the scaffolds showed that the space between the wall of the chamber and the cortex of the scaffold was always smaller than the diameter of the interconnections (ranging from $150 \mu \mathrm{m}$ to $280 \mu \mathrm{m}$ ): $\Delta \mathrm{H}=0$ (due to the piston adjustment on the scaffold) and $10 \mu \mathrm{m} \leq \Delta \mathrm{W} \leq 110 \mu \mathrm{m}$. Micro-CT measurements $(n=4)$ showed an average macropore diameter of $380 \pm 30 \mu \mathrm{m}$ and a $66 \pm 1 \%$ porosity: macropores were uniformly distributed and interconnected. $\mathrm{Hg}$ porosimetry measurements (Fig. 2B), taking into account the "bottleneck" structure of the macropores (Fig. 2C), gave a range of interconnection diameters between $\sim 150$ and $280 \mu \mathrm{m}$. These values were confirmed by SEM image analysis with the ImageJ software (data not shown). The ceramic portion of the scaffold was dense, and its surface displayed few micropores (Fig. 2D).

Stress-strain curves were obtained from macroscopic compression tests (See Fig. 3A for a representative curve). The mean macroscopic modulus $\mathrm{E}_{\text {macro }}$ was $1,591 \pm 41 \mathrm{MPa}$ $\left(n=3\right.$, Fig. 3A) while the microscopic modulus $\left(\mathrm{E}_{\text {micro }}\right)$, obtained by an inverse analysis, was equal to 5,432 MPa. The microscopic modulus was used as input data for the Abaqus ${ }^{\circledR}$ software used for the numerical simulations. As a first approximation, a purely elastic deformation was assumed, even if scaffolds presented with microporosity and microcracks that could create high stress zones leading to a non-elastic behaviour. The strain distributions within the scaffold, obtained through numerical simulations, are shown in Fig. 3B. Strain levels were low at the top and bottom surfaces and moderate along the vertical cortex. Interestingly, the porous region within the scaffold presented higher levels of strains, ranging from $5 \cdot 10^{-4}$ to $10^{-2}$ (Fig. 3C), than the cortical part. More precisely the highest levels were obtained on the struts of material surrounded by pores.

\section{Cell seeding efficiency}

The observation of cell nuclei distribution in scaffolds after seeding revealed that cells were homogeneously distributed in the internal porous part of the scaffold (Fig. 4), with $10,060 \pm 3,700 \mathrm{cell} / \mathrm{cm}^{2}$ ( $n=4$ scaffolds, 15 fields counted/scaffold). It corresponds to $48,500 \pm 17,500$ cell/ scaffold, by assuming 1,030 pores of $380 \mu \mathrm{m}$ average diameter per scaffold (see results section 3.1). In contrast, seeded cells were absent from the side faces of the cortex (image not included).

\section{Optimisation of scaffold perfusion}

To establish the optimal culture medium perfusion conditions for the scaffolds, 3 steady (i.e. non-pulsatile) flow rates were tested in $7 \mathrm{~d}$ cultures: $1 \mathrm{~mL} / \mathrm{min}$, commonly used for 3D cell culture (Bancroft et al., 2003; Cartmell et al., 2003; Grayson et al., 2008; Janssen et al., 2006b), 
$0.5 \mu \mathrm{L} / \mathrm{min}$ (similar to the medium renewal rate of $2 \mathrm{D}$ culture), and $2 \mu \mathrm{L} / \mathrm{min}$. The range of medium velocity corresponding to these volume flow rates, with respect to the minimum and the maximum flow cross-sectional areas assumed in the chamber (Table 3), are displayed in Table 4. A steady flow rate of $1 \mathrm{~mL} / \mathrm{min}$ ensures a complete perfusion of the chamber volume $(600 \mu \mathrm{L})$ in $36 \mathrm{~s}$. It resulted in low final cell density within the scaffolds (Fig. $5 \mathrm{~A})$; the same result was observed with the lowest flow rate tested $(0.5 \mu \mathrm{L} / \mathrm{min}$, Fig. $5 \mathrm{~A})$. Only the steady flow rate of $2 \mu \mathrm{L} / \mathrm{min}$ led to a dense (Fig. 5A) and relatively homogeneous cell distribution in the scaffold interior (i.e. no macropore is devoid of attached cells, Fig. 5B). Moreover, a comparison of the $2 \mu \mathrm{L} / \mathrm{min}$ flow rate with static culture (i.e. without perfusion), both performed in the culture chamber, indicated an increase by $\approx 2$.4-fold of the number of living cells in perfused conditions after $5 \mathrm{~d}$ of culture (Fig. 5C). Accordingly, all results presented further in this article have been obtained with the $2 \mu \mathrm{L} /$ min flow rate.

\section{Cell viability and 3D culture kinetics}

As shown by real-time measurements, $\mathrm{O}_{2}$ concentration at the chamber inlet was always higher than at the outlet (Fig. 6A). The difference remained constant during the first 2 weeks of culture (see overlap of confidence intervals in Fig. $6 \mathrm{~A}$; at $240 \mathrm{~h}$ the $\Delta \mathrm{O}_{2 \text { Inlet-Outlet }} \approx+1.02 \%$, value which was subtracted from $\mathrm{O}_{2 \text { Inlet }}$ to generate Fig. 6B). It increased at later culture times, significantly after $390 \mathrm{~h}(=16 \mathrm{~d}$, see separation of confidence intervals in Fig. 6B) reflecting a progressive decrease of $\mathrm{O}_{2}$ at the chamber outlet. Culture medium temperature remained constant at the nominal value of $37^{\circ} \mathrm{C}$ throughout the culture period.

Scanning electron micrographs showing the morphological aspects of calvarial cells cultured in scaffolds at day 7 (Fig. 7A) indicated that the cells laid down a matrix inside and between the macropores. Cell counting at days 7, 14 and 21 (Fig. 7B) showed an increase in cell numbers inside the scaffolds between seeding and culture day 14, then a slight decrease between day 14 and day 21 . These results were visually observable by the density of cell nuclei in the centre of the scaffolds (Fig. 7B). At day 21, a high density of cell nuclei and ECM was observed at the inlet surface of the scaffolds, filling-up the pores (Fig. not included).

\section{Osteogenesis}

Osteoblast differentiation of primary calvarial osteoprogenitor cells cultured for $14 \mathrm{~d}$ in the scaffolds was evaluated by QRT-PCR. While cultures grown in either osteogenic or standard medium expressed the lineage marker Runx2, its level of expression increased by $60 \%$ in osteogenic medium (Fig. 8A). The expression of early osteoblastic differentiation genes, Osterix (OSX), Alkaline Phosphatase (ALP), Type 1 Collagen (Coll1 $\alpha 1$ ) and Osteopontin (OPN), was considerably increased in osteogenic medium (Fig. 8B), along with late differentiation markers, characteristic of fully mature, active osteoblasts, Osteocalcin (OCN) and Bone Sialoprotein (BSP) (Fig. 8C).

Matrix formation and mineralisation in the scaffold were assessed after $14 \mathrm{~d}$ of osteogenic culture. Both
Table 3. flow cross-sectional area considering $9 * 9$ macropores of $350 \mu \mathrm{m}$ (minimum) or $410 \mu \mathrm{m}$ (maximum) in diameter per cross-section (cubic), or assuming, in the worst case, only one interconnection $\left(\varnothing_{\min }=150 \mu \mathrm{m}\right.$, $\left.\varnothing_{\max }=280 \mu \mathrm{m}\right)$ per macropores, and keeping in mind the fluid flow bypass around the scaffold due to the lateral cross-sectional area $(10 \mu \mathrm{m} \leq \Delta \mathrm{W} \leq 110 \mu \mathrm{m}, \mathrm{H}=5.15$ $\pm 0.05 \mathrm{~mm}$ ).

\begin{tabular}{|l|l|l|l|}
\hline $\begin{array}{l}\text { Cross-sectional } \\
\text { area }\end{array}$ & $\begin{array}{l}\text { Macropore } / \\
\mathbf{m m}^{2}\end{array}$ & $\begin{array}{l}\text { Interconnection } \\
/ \mathbf{m m}^{\mathbf{2}}\end{array}$ & $\begin{array}{l}\text { Lateral/ } \\
\mathbf{m m}^{\mathbf{2}}\end{array}$ \\
\hline Minimum & 7.79 & 1.43 & 0.05 \\
\hline Maximum & 10.69 & 4.99 & 0.57 \\
\hline
\end{tabular}

Table 4. medium velocities within the scaffold calculated from the volume flow rates and the flow cross-sectional areas (C-SA) assumed in the chamber (Table 3). "MAX" and "min" medium velocities correspond to (Flow rate / sum minimum cross-sectional areas), and (Flow rate / sum maximum cross-sectional areas), respectively.

\begin{tabular}{|c|c|c|c|}
\hline \multirow{2}{*}{$\begin{array}{c}\text { Volume } \\
\text { flow rate } \\
/ \boldsymbol{\mu} \mathbf{L ~ m i n}^{-1}\end{array}$} & \multicolumn{3}{|c|}{ Medium velocity with respect to } \\
\cline { 2 - 4 } & & $\begin{array}{c}\text { (Macropore }+ \\
\text { Lateral) C-SA } \\
/ \boldsymbol{\mu} \mathbf{~ s}^{-1}\end{array}$ & $\begin{array}{c}\text { (Interconnection } \\
\text { + Lateral) C-SA } \\
/ \boldsymbol{\mu} \mathbf{~ s}^{-1}\end{array}$ \\
\hline \multirow{2}{*}{1000} & MAX & 2,125 & 11,243 \\
\cline { 2 - 4 } & min & 1,479 & 2,998 \\
\hline \multirow{2}{*}{2} & MAX & 4.2 & 22.5 \\
\cline { 2 - 4 } & min & 3.0 & 6.0 \\
\hline \multirow{2}{*}{0.5} & MAX & 1.1 & 5.6 \\
\cline { 2 - 4 } & min & 0.7 & 1.5 \\
\hline
\end{tabular}

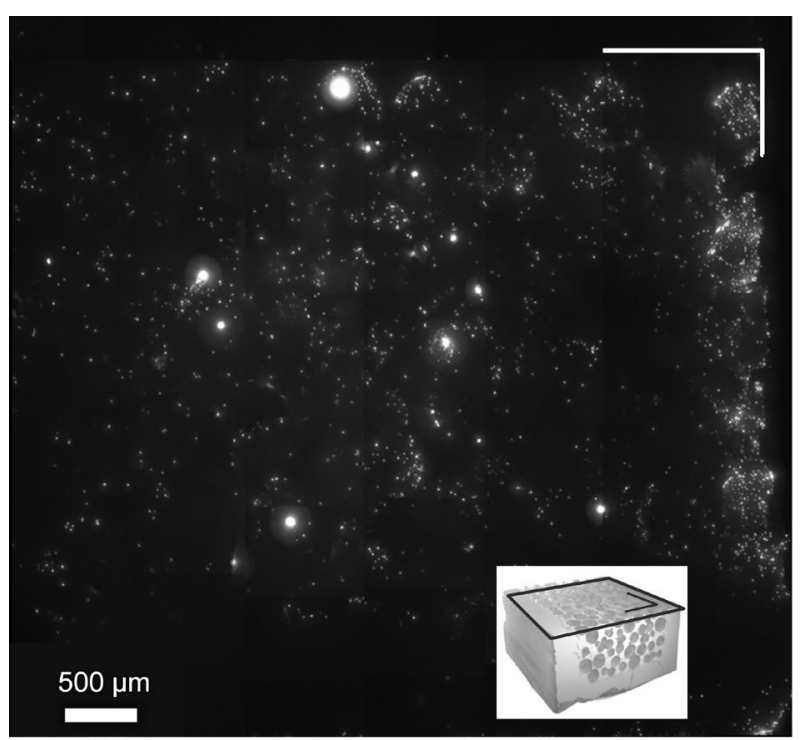

Fig. 4. Scaffold seeding. Distribution of DAPI stained cell nuclei in the scaffold interior after seeding. Picture of the area outlined in black on the $\mu \mathrm{CT}$ image; the orientation is given by the perpendicular bars.

Fibronectin (FN) and Coll1 $\alpha 1$ networks appeared within the macropores and were co-localised with DAPIlabelled cell nuclei (green or blue dots in Fig. 9B and C respectively). Moreover, both osteoblast differentiation and mineralised matrix deposition, revealed by alkaline phosphatase (ALP) activity and alizarin red staining, 

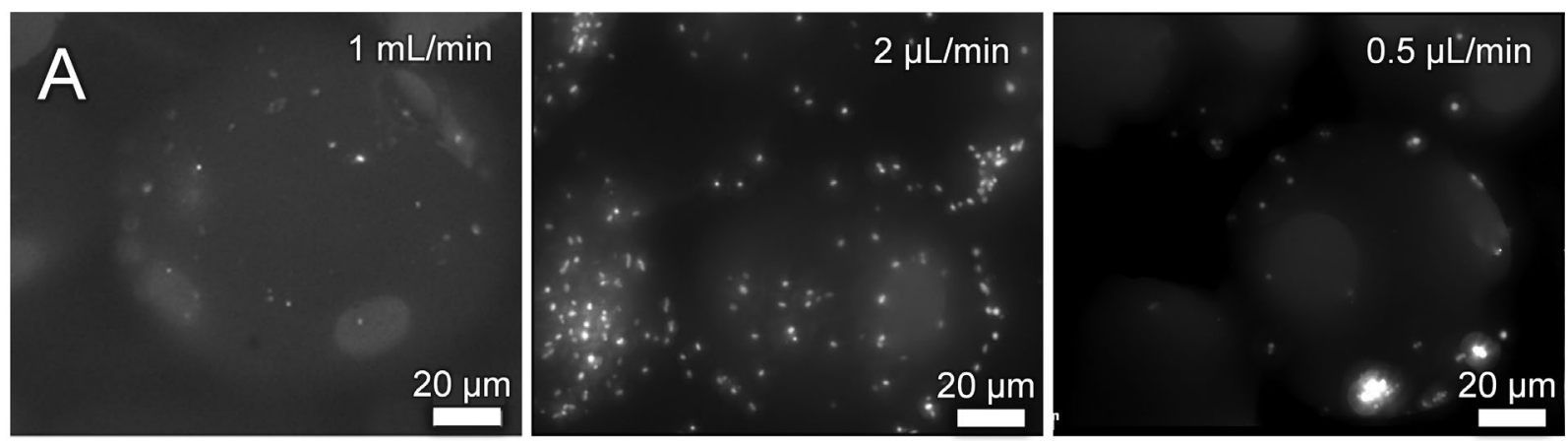

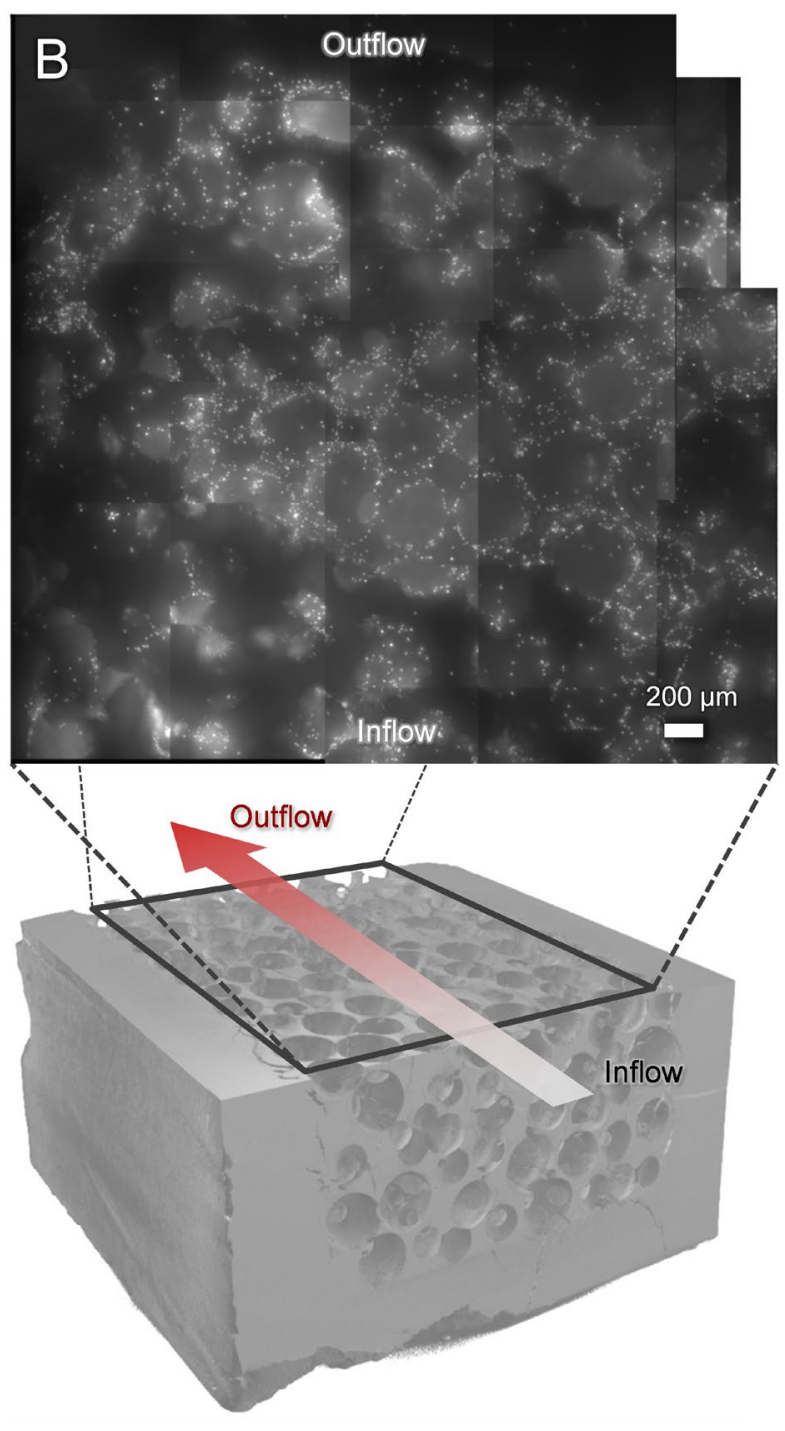

C

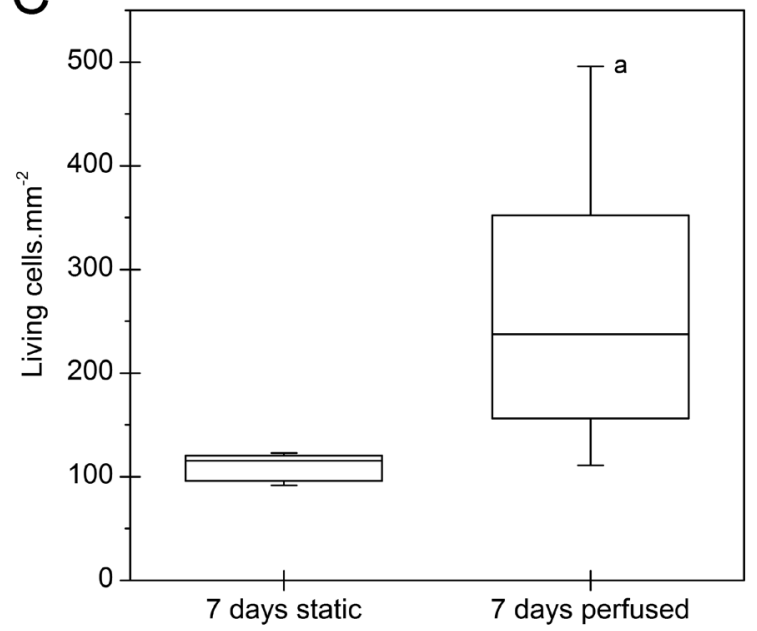

Fig. 5. Optimisation of perfusion flow. (A) Micrographs of DAPI stained cell nuclei in scaffolds perfused with different fluid flow rates for $7 \mathrm{~d}$. (B) Nuclei distribution inside the scaffold after $7 \mathrm{~d}$ of culture. (C) Cell density/ $\mathrm{mm}^{2}$ of interior pore area, in scaffolds after $7 \mathrm{~d}$ of culture under static and dynamic $(2 \mu \mathrm{L} / \mathrm{min})$ conditions. $(n=4$ scaffolds/culture condition, a: $p<0.05 v s$. Static, MannWhitney U Test).

respectively, were observed in the porous part of the scaffold (Fig. 9D).

\section{Effect of mechanical stimulation on gene expression}

Expression of C-fos and OPN, both early response genes to mechanical loading, as well as the early differentiation gene OSX was analysed by QRT-PCR, 20 min and $2 \mathrm{~d}$ after mechanical stimulation at day 5 of the culture (Fig. 10A). While no effect of mechanical loading was observed $2 \mathrm{~d}$ after stimulation (results not shown), QRT-PCR analysis 20 min after stimulation showed an overexpression of $\mathrm{C}$-fos in stimulated scaffolds, with no effect on OSX or OPN (Fig. 10B).

\section{Discussion}

The bioceramic developed for our study was optimised to be efficiently perfused and mechanically stimulated. The $\approx 66 \%$ interconnected macroporosity, previously reported as an optimal value (Okamoto et al., 2006), associated with a dense shell limiting medium flow bypass between the chamber wall and the scaffold sides, was homogeneously seeded and perfused. More generally, the high control of macropore and interconnection diameters, micropore density, phase and chemical composition of the scaffolds, as well as the setting up of appropriate seeding and perfusion protocols allowed uniform cell colonisation 
Fig. 6. Oxygen concentration monitoring. (A) Dissolved $\mathrm{O}_{2}$ concentrations measured before (inlet) and after (outlet) the culture chamber for $21 \mathrm{~d}$ of culture $(504 \mathrm{~h})$ at $2 \mu \mathrm{L} /$ min. Dots are individual measurements. The progressive drop in outlet oxygen concentrations has been highlighted in (B) by subtracting from inlet values the $\Delta \mathrm{O}_{2 \text { Inlet-Outlet }}$ observed at $240 \mathrm{~h}(+1.02 \%)$. Coloured bands outline the $95 \%$ confidence interval of the values calculated from linear $(<240 \mathrm{~h})$ or $4^{\text {th }}$ degree polynomial $(>240 \mathrm{~h})$ fitted curves. The Figure was simplified by omitting values between $170 \mathrm{~h}$ and $240 \mathrm{~h}$, during which no significant evolution of $\mathrm{O}_{2}$ concentrations was observed.
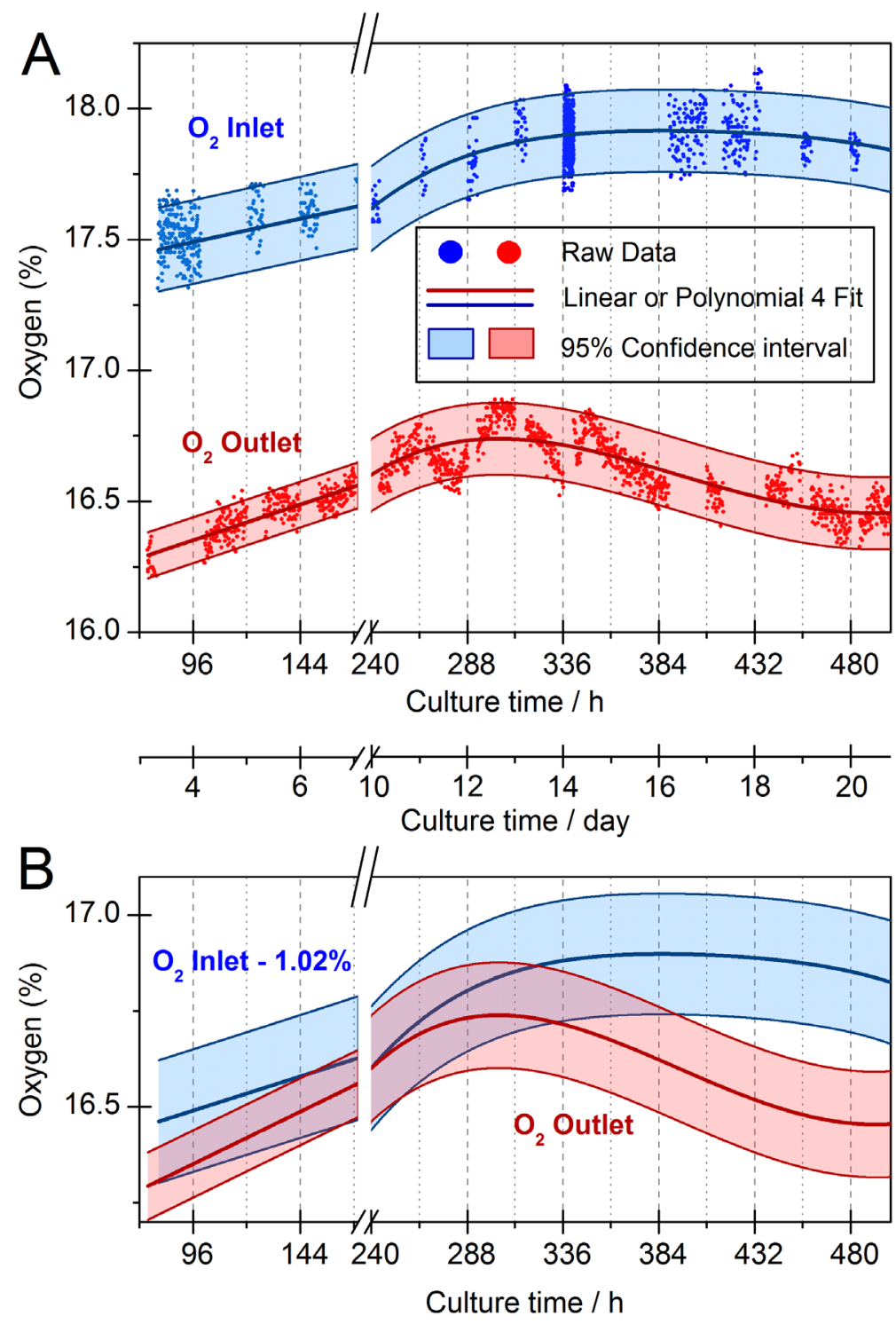

and distribution in the scaffold macropores, which make it possible to perform reproducible cell cultures. Besides the effect of the cortical part on perfusion, this feature also improved the global mechanical properties of the scaffolds and their ability to withstand high mechanical loading with a macroscopic and microscopic elastic modulus of 1.6 GPa and 5.4 GPa, respectively. These values are similar to what has been reported for human trabecular bone tissue (Guo, 2000), where the macroscopic elastic modulus varies between 1 and $5 \mathrm{GPa}$ depending on the anatomical site and age, while the microscopic modulus (obtained by nanoindentation) ranges from $11 \mathrm{GPa}$ to $18 \mathrm{GPa}$ (Guo, 2000).

It is well known that the mechanical properties of scaffolds affect cellular behaviour and fate (Bouet et al., $2015 b)$. Indeed, cells have the ability to sense and probe the stiffness of their surroundings as they adhere and interact with the extracellular matrix (ECM) (Discher et al., 2005). Consequently, scaffolds for osteogenesis often contain ceramic hydroxyapatite, whose stiffness is similar to bone (Abousleiman and Sikavitsas, 2006;
Bonassar and Vacanti, 1998). Engler et al. have shown that mesenchymal stem cells (MSC) differentiate into different cell types based upon substrate stiffness and, in particular, that MSCs cultivated on a hard substrate (gel-based) become osteogenic cells (Engler et al., 2006). Assuming a relationship between the elastic modulus and material stiffness (Chiesa, 2012), it appeared that the bioceramic developed for this study possesses sufficient stiffness to promote osteogenic differentiation. According to the numerical results, the highest strain values in loaded scaffolds would reach $\approx 0.01$, similar to strains experienced by in vivo bone tissue during walking (between 0.0024 and 0.0125, according to Al Nazer et al. (Al Nazer et al., 2012)). This suggests that the scaffold architecture would deliver the appropriate stimuli as it reproduces the in vivo mechanical competence. Finally, the homogeneous stress distribution in the porous part of the scaffold, emphasised by numerical simulation, indicates that the strategy of applying the load on a flat bioceramic surface is mechanically relevant and allows accurate control of cell mechanical stimulation. 

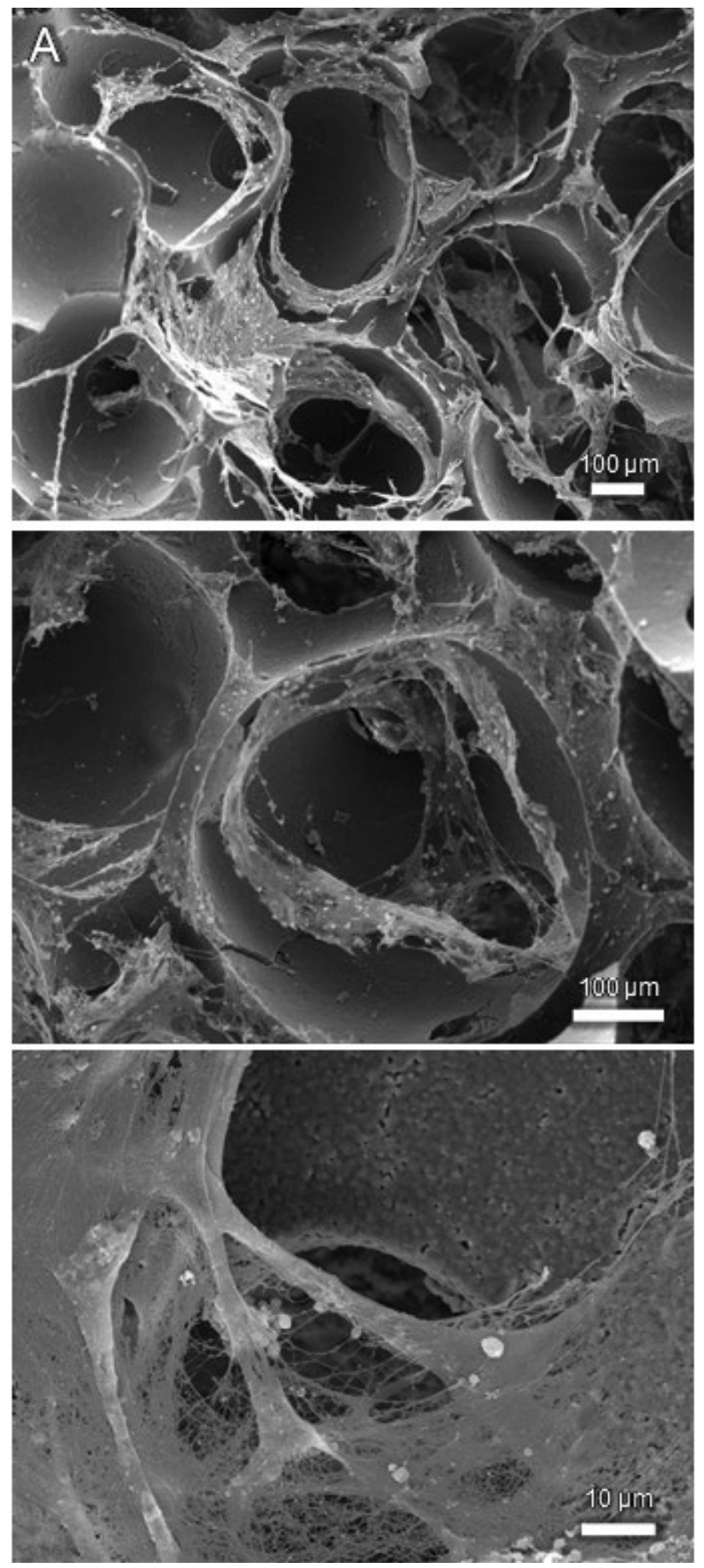

These observations were confirmed by the mechanical stimulation of the chambers with the Zetos ${ }^{\circledR}$ device at day 5 . That the samples respond to loading by overexpressing $\mathrm{C}$-fos $20 \mathrm{~min}$ after stimulation validates our bioreactor system as a tool to assess the action of mechanical signals on $3 \mathrm{D}$ bone cultures in vitro. The lack of effect of our loading regimen on the other early-response gene to mechanical challenge, OPN, nor on OSX or on longer term ( 2 d) marker gene expression, likely reflects the inadequacy of the parameters chosen for our experiments (e.g. stress amplitude, duration and frequency of chargedischarge cycles, sampling time after stimulation respective to the gene expression window). In addition, the wide range of values observed after stimulation (see

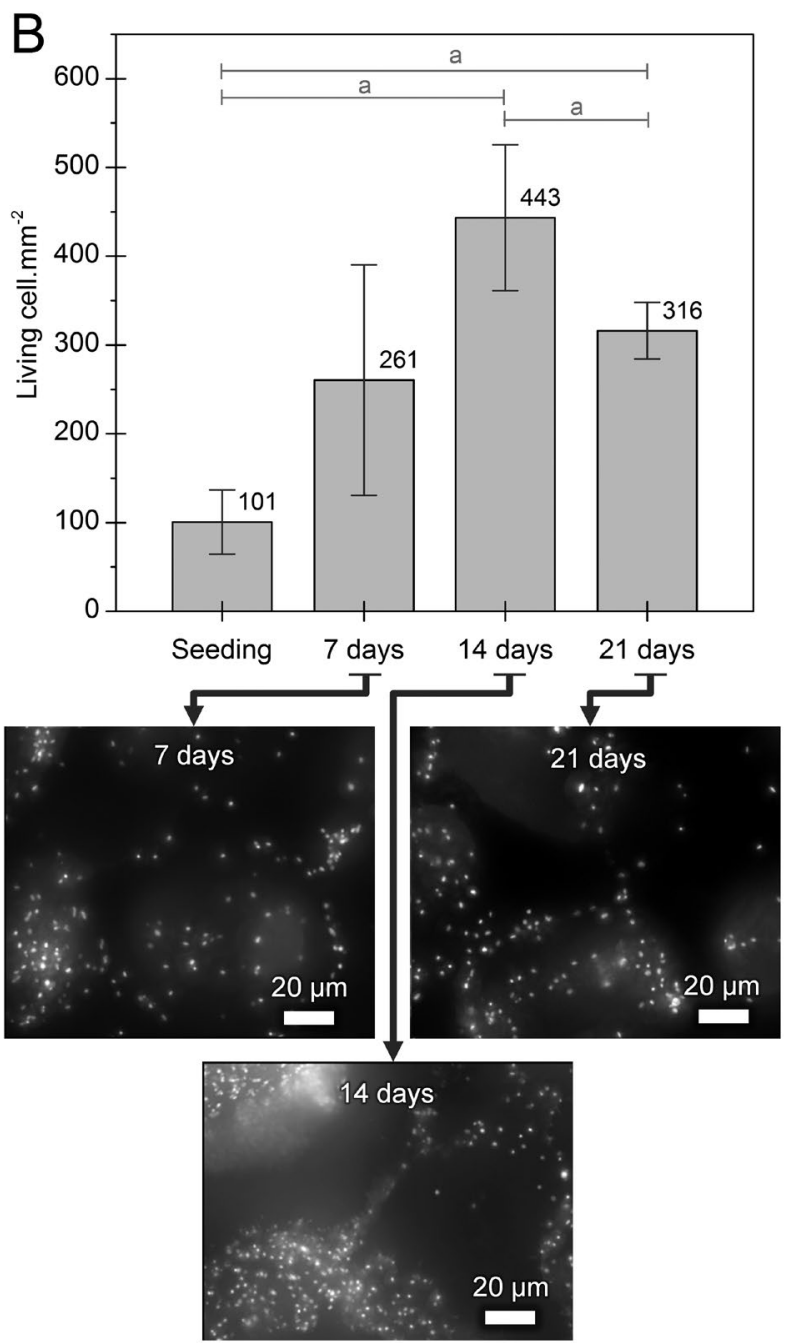

Fig. 7. Matrix deposition and cell growth within the cultured scaffolds. (A) SEM micrographs of the scaffold interior after $7 \mathrm{~d}$ of culture at $2 \mu \mathrm{L} / \mathrm{min}$. (B) Cell density/ $\mathrm{mm}^{2}$ of interior pore area, in freshly seeded scaffolds and after 7, 14 and $21 \mathrm{~d}$ of culture; $n=4$ scaffolds/time point, a: $p<0.05$. Micrographs illustrate the density of DAPI stained cell nuclei in scaffolds at each culture time.

Fig. 10B) suggests that beyond inter-culture variability, experimental conditions (e.g. chamber manipulation) were not sufficiently standardised. Further work will thus be required to refine the loading regimen and protocol, and find the appropriate conditions for an optimal response of the cultures, which is beyond the goal of this tool-validation work.

Seeding cells in bioceramics is the first step in establishing a 3D cell culture. This step plays a crucial role in the progression of tissue formation since it should allow a uniform cell distribution and high cellularity (Vunjak-Novakovic and Freed, 1998). Although static seeding is the most commonly used method, low seeding efficiencies and non-uniform cell distributions are often 
reported (Alvarez-Barreto and Sikavitsas, 2007; Burg et al., 2000; Holy et al., 2000). Therefore, based on the literature (Du et al., 2009; Godbey et al., 2004; Janssen et al., 2006a), a dynamic seeding technique was used in this study. Combined with the architecture of the scaffolds, this resulted in a uniform cell colonisation and distribution within the scaffold interior. Seeding of scaffolds led to a starting cell density $\left(\approx 10,000\right.$ cells $\left./ \mathrm{cm}^{2}\right)$ for this specific cell type, which is close to standard plating densities on plastic (e.g. 5,000 cells $/ \mathrm{cm}^{2}$, (Bouet et al., 2015a)). Mouse calvaria cells grown in 2D at this cell density form osteoblast colonies expressing bone markers and laying down an osteoid matrix which mineralises as HA (bone nodules (Bellows et al., 1998). Such cultures thus realise in vitro primary bone tissue formation (Malaval et al., 1999).

Once seeded, the scaffolds were inserted in the perfusion bioreactor for long term culture. Our bioreactor has been made simple, with a minimum number of parts, in order to facilitate handling and limit contamination.

Constant perfusion flow rates for $3 \mathrm{D}$ cultures reported in the literature range between 1 (Bernhardt et al., 2008) and $10 \mathrm{~mL} / \mathrm{min}$ (Jagodzinski et al., 2008). The wide range of flow rate values used in these models is potentially due to differences in overall design of the bioreactors and more specifically the fitting of the scaffolds in culture chambers. In our bioreactor, a fluid flow of $1 \mathrm{~mL} / \mathrm{min}$ (equivalent to a medium velocity range of 1,480 to $11,200 \mu \mathrm{m} / \mathrm{s}$ ) proved to be deleterious for cells, as this rate probably exceeds a critical value, inducing cell death or their washing out due to excessive shear stress (Cartmell et al., 2003; Singh et al., 2007). Indeed, whereas our system confines the fluid flow inside the scaffold, many perfusion bioreactors display medium flow bypass, decreasing the actual flow experienced by cells within the scaffolds (Dumas et al., 2009; Uemura et al., 2003; Wang et al., 2003). A $2 \mu \mathrm{L} /$ min unidirectional steady flow $(3 \leq$ Medium velocity $\leq 23 \mu \mathrm{m} / \mathrm{s}$ ) maintained for $14 \mathrm{~d}$ results in homogeneous cell distribution and matrix deposition into the scaffold interior, indicating that this flow profile combined with the bioceramic features allow cells to uniformly grow in this artificial environment. The perfusion setting enhances delivery of nutrients throughout the scaffold and maintains constant oxygen levels, at values equivalent to $2 \mathrm{D}$ culture $(\approx 21 \%)$, for about $16 \mathrm{~d}$. The positive difference of oxygen concentration between the inlet and outlet of the chamber for the first $16 \mathrm{~d}\left(\Delta \mathrm{O}_{2 \text { Inlet-Outlet }} \approx+1.02 \%\right)$ emphasises the metabolic consumption of $\mathrm{O}_{2}$ by cultured cells. This result is consistent with those observed in other studies run for a shorter culture time (up to 7 d) (Abaci et al., 2012; Janssen et al., 2006a; Volkmer et al., 2012).

Real-time QRT-PCR results show significantly increased expression levels of all osteoblastic genes, including Runx 2 , after $14 \mathrm{~d}$ of culture at $2 \mu \mathrm{L} / \mathrm{min}$ under osteogenic conditions. Increased expression of Runx2 indicates that the cells grown under these conditions commit to the osteoblastic lineage. The FN layer observed on the pore surfaces is consistent with osteoid deposition (Sottile et al., 2002), during which the FN network serves as a pattern for subsequent laying of Coll1 $\alpha 1$ fibres. The overexpression of early osteoblast-specific genes under osteogenic conditions, including OSX, Coll1 $\alpha 1$, ALP
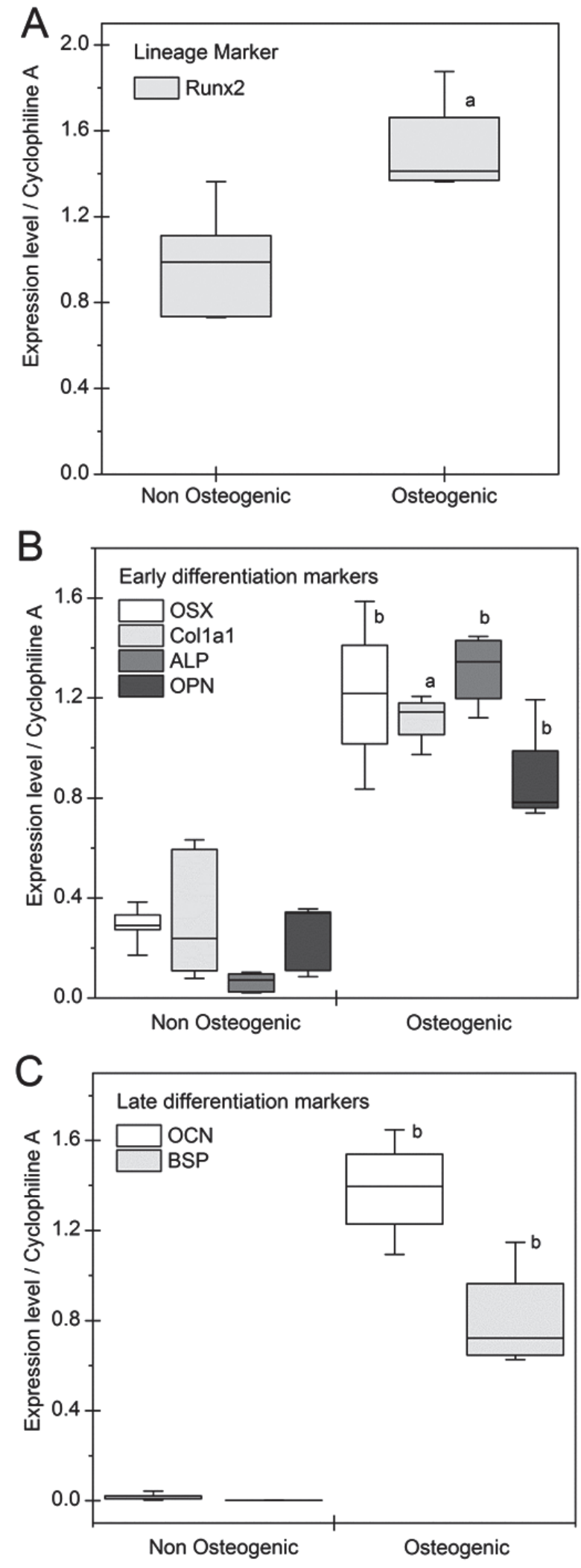

Fig. 8. Osteoblast marker expression in $3 \mathrm{D}$ primary calvaria cell cultures grown in scaffolds for $14 \mathrm{~d}$ under $2 \mu \mathrm{L} /$ min perfusion. (A) Lineage, (B) early and (C) late differentiation marker gene expression (normalised to cyclophilin A) assayed in osteogenic and non osteogenic culture conditions; explanation of the abbreviations in Table 2. Box-plots for $n=5-6$ scaffolds/group; a: $p<0.05$ and $\mathbf{b}: p<0.01 v s$. gene-matched non osteogenic conditions, Mann-Whitney U Test. 

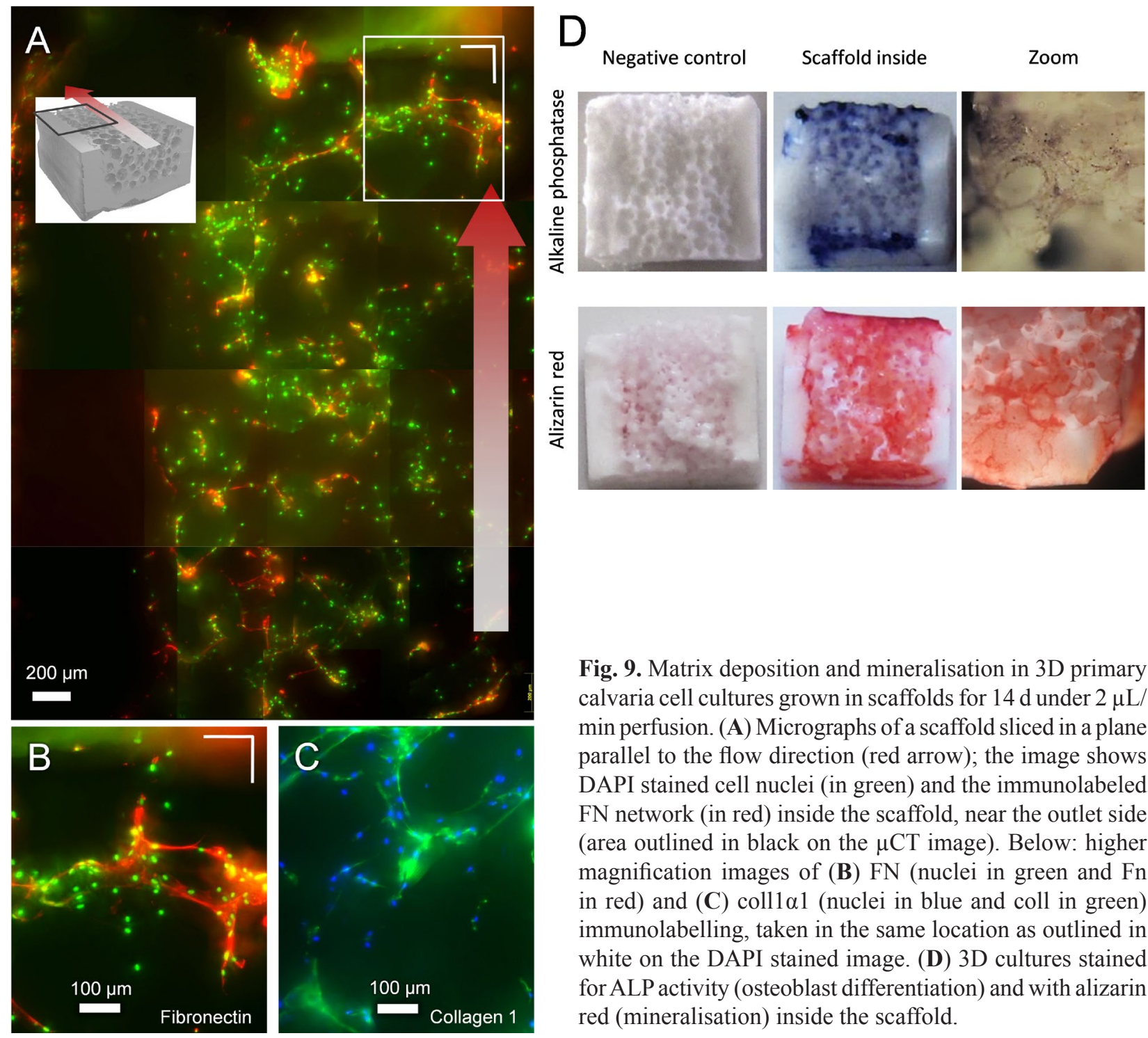

Fig. 9. Matrix deposition and mineralisation in 3D primary calvaria cell cultures grown in scaffolds for $14 \mathrm{~d}$ under $2 \mu \mathrm{L} /$ min perfusion. (A) Micrographs of a scaffold sliced in a plane parallel to the flow direction (red arrow); the image shows DAPI stained cell nuclei (in green) and the immunolabeled FN network (in red) inside the scaffold, near the outlet side (area outlined in black on the $\mu \mathrm{CT}$ image). Below: higher magnification images of (B) FN (nuclei in green and Fn in red) and (C) coll1 $\alpha 1$ (nuclei in blue and coll in green) immunolabelling, taken in the same location as outlined in white on the DAPI stained image. (D) 3D cultures stained for ALP activity (osteoblast differentiation) and with alizarin red (mineralisation) inside the scaffold.

and OPN, confirms osteogenic differentiation. Enhanced expression of mature osteoblast marker OCN and BSP indicates that at least part of the cells in the scaffold are fully differentiated and able to mineralise the matrix, as confirmed by alizarin red staining. Overall, these results prove that primary bone formation can be induced in this $3 \mathrm{D}$ culture system by perfusing the scaffolds with a steady fluid flow of osteogenic medium.

After $21 \mathrm{~d}$ of culture, the high matrix density observed at the scaffold inlet obstructs the pores, likely resulting in overall loss of scaffold perfusion homogeneity and finally leading to cell death in the scaffold interior (Fig. 7B). This perfusion homogeneity problem seems to appear after about $16 \mathrm{~d}$ of culture as revealed by the increase of $\Delta \mathrm{O}_{2}$ Inlet-Outlet (Fig. 6). Therefore, the engineered in vitro $3 \mathrm{D}$ cell culture system developed in this study is likely optimised for intermediate term applications, spanning about 2 weeks of culture. Longer time experiments will require adjustment of the $3 \mathrm{D}$ culture system involving scaffold features (e.g. macro-scale architecture) and/or perfusion parameters. As discussed elsewhere (Bouet et al., 2015b), computed modelling will likely be the best and cheapest way to predict the effects of scaffold architecture or perfusion modifications on the macro- and microenvironmental cues (e.g. shear stress) that affect cell behaviour and fate.

\section{Conclusions}

The goal of this study was to create an engineered in vitro $3 \mathrm{D}$ cell culture system combining a perfusion bioreactor and a cubic calcium phosphate scaffold in an effort to improve upon existing systems concerning controlling the culture (e.g. perfusion, culture time) and mechanical stimulation of seeded cells. This was a proof-of-concept study for controlled and homogeneous osteoblastic cell culture in a perfused $3 \mathrm{D}$ culture system allowing mechanical loading. An original cubic macroporous calcium phosphate bioceramic was produced which allows reproducible cell culture for at least $15 \mathrm{~d}$. After an efficient cell seeding of the scaffold, this system permits calvarial cells to grow uniformly without any contamination, and conducts calvarial cell from multiplication to matrix mineralisation 


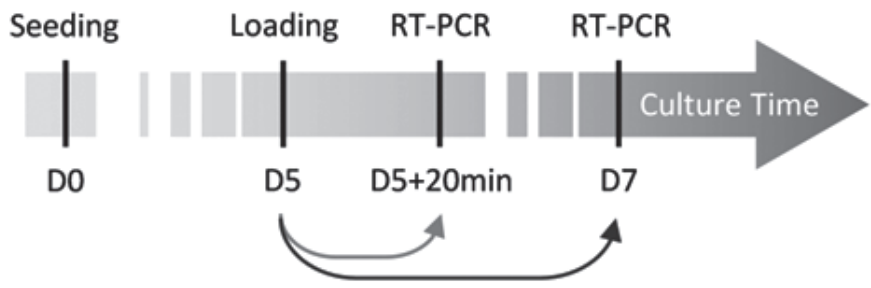

Fig. 10. Effect of mechanical loading on gene expression. (A) Experimental design starting with cell seeding in the scaffolds at D0, with mechanical stimulation for $15 \mathrm{~min}$ in the Zetos device after $5 \mathrm{~d}$ of culture under perfusion $(2 \mu \mathrm{L} / \mathrm{min})$, followed by an additional $20 \mathrm{~min}$ or $2 \mathrm{~d}$ of culture. (B) $20 \mathrm{~min}$ after loading, RNA was extracted and gene expression of OSX, OPN and C-fos were measured by QRT-PCR. Box-plots for $n=5-6$ scaffolds/group; a: $p<0.05 v s$. gene-matched Control (= non stimulated scaffolds), MannWhitney U Test. Please note the log scale.

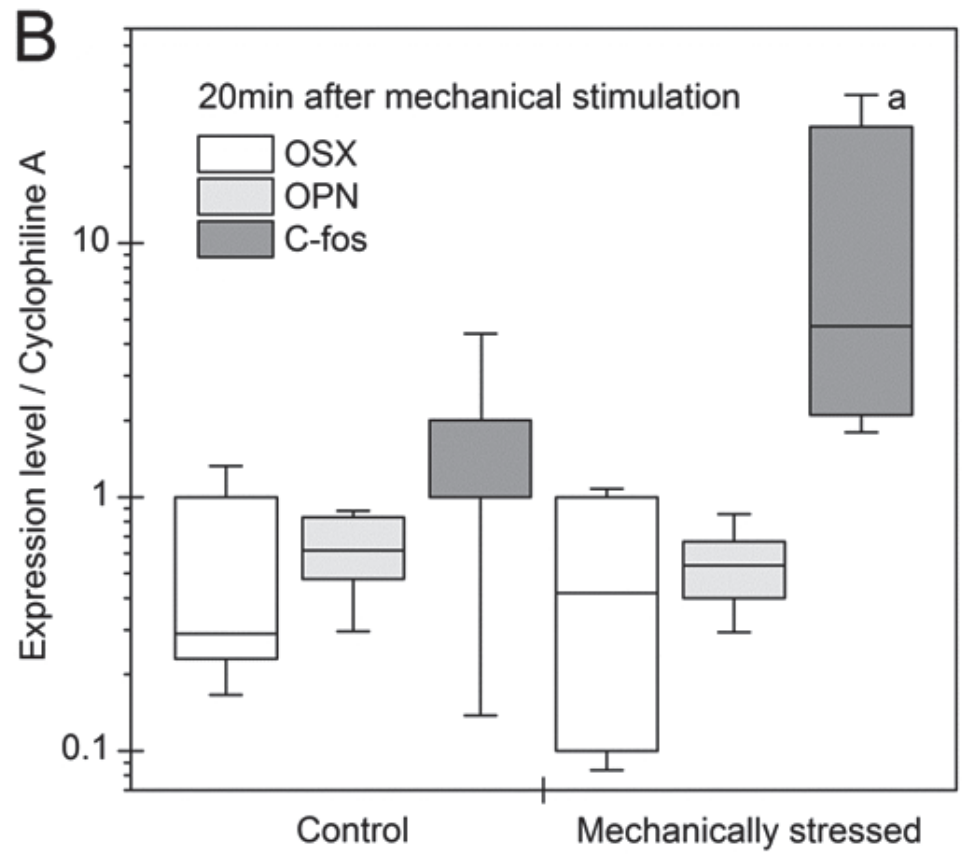

in osteogenic medium. This is achieved with accurate control (e.g. sterility, mass transfer) and monitoring (e.g. $\mathrm{O}_{2}$ ) of key cell culture parameters similar to 2D models, but in conditions more physiologically similar to bone in vivo. As expected from numerical modelling, the scaffold is able to withstand high mechanical loading, to reproduce the main mechanical competence of bone (e.g. stiffness, strain range), and so to deliver appropriate stimuli to cells. However, some technical and settings adjustments will still be required to refine the loading regimen for osteogenesis or to be able to perform long term culture ( $>2$ weeks).

Bioreactor-based 3D model systems are powerful in vitro tools, which can potentially limit the experimental use of animal models. Eventually, such systems will facilitate the understanding of structure-function relationships under normal and pathological conditions. Moreover, they will provide tools for bench-testing factors in toxicological or pharmacological studies.

\section{Acknowledgements}

We thank Marc Binet from System Industrie (Pierrelatte, France) for lending us the Presens transmitter device, Laurent Navarro, Jérôme Molimard, Jin A Ko (ENSM-SE), Fiona Louis, Alexis Vallard and Norbert Laroche (LBTO) for their technical help, and Nicolas Curt (ENSM-SE) for the bioreactor manufacturing. The study was funded by the European Space Agency (ERISTO program, CCN n`8 ESTEC, contract number 4200014232 - formerly $14232 / 00 / \mathrm{NN} / \mathrm{SH}$ ) and the French Ministry of Research (PhD fellowship to Guenaelle Bouet).

\section{References}

Abaci HE, Devendra R, Smith Q, Gerecht S, Drazer $G$ (2012) Design and development of microbioreactors for long-term cell culture in controlled oxygen microenvironments. Biomed Microdevices 14: 145-152.

Abousleiman RI, Sikavitsas VI (2006) Bioreactors for tissues of the musculoskeletal system. Adv Exp Med Biol 585: 243-259.

Al Nazer R, Lanovaz J, Kawalilak C, Johnston JD, Kontulainen S (2012) Direct in vivo strain measurements in human bone-a systematic literature review. J Biomech 45: 27-40.

Alvarez-Barreto JF, Sikavitsas VI (2007) Improved mesenchymal stem cell seeding on RGD-modified poly(Llactic acid) scaffolds using flow perfusion. Macromol Biosci 7: 579-588. 
Anselme K (2011) Biomaterials and interface with bone. Osteoporos Int 22: 2037-2042.

Bakker AD, Klein-Nulend J (2012) Osteoblast isolation from murine calvaria and long bones. Methods Mol Biol 816: 19-29.

Bancroft GN, Sikavitsas VI, Mikos AG (2003) Design of a flow perfusion bioreactor system for bone tissueengineering applications. Tissue Eng 9: 549-554.

Bellows CG, Ciaccia A, Heersche JN (1998) Osteoprogenitor cells in cell populations derived from mouse and rat calvaria differ in their response to corticosterone, cortisol, and cortisone. Bone 23: 119-125.

Bernhardt A, Lode A, Boxberger S, Pompe W, Gelinsky M (2008) Mineralised collagen - an artificial, extracellular bone matrix - improves osteogenic differentiation of bone marrow stromal cells. J Mater Sci Mater Med 19: 269-275.

Bolgen N, Yang Y, Korkusuz P, Guzel E, El Haj AJ, Piskin E (2008) Three-dimensional ingrowth of bone cells within biodegradable cryogel scaffolds in bioreactors at different regimes. Tissue Eng Part A 14: 1743-1750.

Bonassar LJ, Vacanti CA (1998) Tissue engineering: the first decade and beyond. J Cell Biochem Suppl 30-31: 297-303.

Bose S, Vahabzadeh S, Bandyopadhyay A (2013) Bone tissue engineering using 3D printing. Materials Today 16: 496-504.

Bouet G, Bouleftour W, Juignet L, Linossier MT, Thomas M, Vanden-Bossche A, Aubin JE, Vico L, Marchat D, Malaval L (2015a) The impairment of osteogenesis in bone sialoprotein (BSP) knockout calvaria cell cultures is cell density dependent. PloS One 10: e0117402.

Bouet G, Marchat D, Cruel M, Malaval L, Vico L (2015b) In vitro three-dimensional bone tissue models: from cells to controlled and dynamic environment. Tissue Eng Part B Rev 21: 133-156.

Boyan BD, Hummert TW, Dean DD, Schwartz Z (1996) Role of material surfaces in regulating bone and cartilage cell response. Biomaterials 17: 137-146.

Burdick JA, Vunjak-Novakovic G (2009) Engineered microenvironments for controlled stem cell differentiation. Tissue Eng Part A 15: 205-219.

Burg K, Porter S, Kellam J (2000) Biomaterial development for bone tissue engineering. Biomaterials 21: 2347-2359.

Cartmell SH, Porter BD, Garcia AJ, Guldberg RE (2003) Effects of medium perfusion rate on cell-seeded three-dimensional bone constructs in vitro. Tissue Eng 9: 1197-1203.

Cartmell SH, Rathbone S, Jones G, Hidalgo-Bastida LA (2011) 3D sample preparation for orthopaedic tissue engineering bioreactors. Methods Mol Biol 695: 61-76.

Chiesa RC, A. (2012) Biomimetic, bioresponsive, and bioactive materials : integrating materials with tissue. In: Biomimetic, bioresponsive, and bioactive materials (S.M.P.G. J., ed), Wiley, pp 141-160.

David V, Guignandon A, Martin A, Malaval L, LafageProust MH, Rattner A, Mann V, Noble B, Jones DB, Vico L (2008) Ex Vivo bone formation in bovine trabecular bone cultured in a dynamic $3 \mathrm{D}$ bioreactor is enhanced by compressive mechanical strain. Tissue Eng Part A 14: 117-126.
Davies CM, Jones DB, Stoddart MJ, Koller K, Smith E, Archer CW, Richards RG (2006) Mechanically loaded ex vivo bone culture system 'Zetos': systems and culture preparation. Eur Cell Mater 11: 57-75.

Descamps M, Duhoo T, Monchau F, Lu J, Hardouin P, Hornez JC, Leriche A (2008) Manufacture of macroporous beta-tricalcium phosphate bioceramics. J Eur Ceram Soc 28: 149-157.

Discher DE, Janmey P, Wang YL (2005) Tissue cells feel and respond to the stiffness of their substrate. Science 310: 1139-1143.

Du D, Furukawa KS, Ushida T (2009) 3D culture of osteoblast-like cells by unidirectional or oscillatory flow for bone tissue engineering. Biotechnol Bioeng 102: 16701678.

Dumas V, Perrier A, Malaval L, Laroche N, Guignandon A, Vico L, Rattner A (2009) The effect of dual frequency cyclic compression on matrix deposition by osteoblast-like cells grown in 3D scaffolds and on modulation of VEGF variant expression. Biomaterials 30: 3279-3288.

Elsdale T, Bard J (1972) Collagen substrata for studies on cell behavior. J Cell Biol 54: 626-637.

Engler AJ, Sen S, Sweeney HL, Discher DE (2006) Matrix elasticity directs stem cell lineage specification. Cell 126: 677-689.

Godbey WT, Hindy SB, Sherman ME, Atala A (2004) A novel use of centrifugal force for cell seeding into porous scaffolds. Biomaterials 25: 2799-2805.

Goldstein AS, Juarez TM, Helmke CD, Gustin MC, Mikos AG (2001) Effect of convection on osteoblastic cell growth and function in biodegradable polymer foam scaffolds. Biomaterials 22: 1279-1288.

Grayson WL, Bhumiratana S, Cannizzaro C, Chao PH, Lennon DP, Caplan AI, Vunjak-Novakovic G (2008) Effects of initial seeding density and fluid perfusion rate on formation of tissue-engineered bone. Tissue Eng Part A 14: 1809-1820.

Grayson WL, Vunjak-Novakovic G, Obradovic B (2012)Bioreactors in tissue engineering. In: Cell and Tissue Engineering (B. Obradović, ed), Springer Berlin Heidelberg, Belgrade, Serbia, pp 217-227.

Guo XE (2000) Mechanical properties of cortical bone and cancellous bone tissue. In: Bone mechanics handbook (C.S.C., ed), CRC Press, Florida.

Holy CE, Shoichet MS, Davies JE (2000) Engineering three-dimensional bone tissue in vitro using biodegradable scaffolds: investigating initial cell-seeding density and culture period. J Biomed Mater Res 51: 376-382.

Jagodzinski M, Breitbart A, Wehmeier M, Hesse E, Haasper C, Krettek C, Zeichen J, Hankemeier S (2008) Influence of perfusion and cyclic compression on proliferation and differentiation of bone marrow stromal cells in 3-dimensional culture. J Biomech 41: 1885-1891.

Janssen FW, Hofland I, van Oorschot A, Oostra J, Peters H, van Blitterswijk CA (2006a) Online measurement of oxygen consumption by goat bone marrow stromal cells in a combined cell-seeding and proliferation perfusion bioreactor. J Biomed Mater Res A 79: 338-348.

Janssen FW, Oostra J, Oorschot A, van Blitterswijk CA (2006b) A perfusion bioreactor system capable of producing clinically relevant volumes of tissue-engineered 
bone: in vivo bone formation showing proof of concept. Biomaterials 27: 315-323.

Jones DB, Broeckmann E, Pohl T, Smith EL (2003) Development of a mechanical testing and loading system for trabecular bone studies for long term culture. Eur Cell Mater 5: 48-60.

Liu C, Abedian R, Meister R, Haasper C, Hurschler C, Krettek C, von Lewinski G, Jagodzinski M (2012) Influence of perfusion and compression on the proliferation and differentiation of bone mesenchymal stromal cells seeded on polyurethane scaffolds. Biomaterials 33: $1052-$ 1064.

Lutolf MP, Gilbert PM, Blau HM (2009) Designing materials to direct stem-cell fate. Nature 462: 433-441.

Malaval L, Liu F, Roche P, Aubin JE (1999) Kinetics of osteoprogenitor proliferation and osteoblast differentiation in vitro. J Cell Biochem 74: 616-627.

McCoy RJ, O’Brien FJ (2010) Influence of shear stress in perfusion bioreactor cultures for the development of three-dimensional bone tissue constructs: a review. Tissue Eng Part B Rev 16: 587-601.

Melchels FPW, Barradas AMC, van Blitterswijk CA, de Boer J, Feijen J, Grijpma DW (2010) Effects of the architecture of tissue engineering scaffolds on cell seeding and culturing. Acta Biomater 6: 4208-4217.

Okamoto M, Dohi Y, Ohgushi H, Shimaoka H, Ikeuchi M, Matsushima A, Yonemasu K, Hosoi H (2006) Influence of the porosity of hydroxyapatite ceramics on in vitro and in vivo bone formation by cultured rat bone marrow stromal cells. J Mater Sci Mater Med 17: 327-336.

Owen SC, Shoichet MS (2010) Design of threedimensional biomimetic scaffolds. J Biomed Mater Res A 94: 1321-1331.

Pecqueux F, Tancret F, Payraudeau N, Bouler JM (2010) Influence of microporosity and macroporosity on the mechanical properties of biphasic calcium phosphate bioceramics: Modelling and experiment. J Eur Ceram Soc 30: $819-829$.

Rawsterne RE, Todd SJ, Gough JE, Farrar D, Rutten FJM, Alexander MR, Ulijn RV (2007) Cell spreading correlates with calculated $\log \mathrm{P}$ of amino acid-modified surfaces. Acta Biomater 3: 715-721.

Raynaud SC, E.; Bernache-Assolant D.; Laval J.P. (2001) Determination of calcium/phosphorus atomic ratio of calcium phosphate apatites using X-ray diffractometry. J Am Ceram Soc 84: 359-366.

Salerno A, Guarnieri D, Iannone M, Zeppetelli S, Netti PA (2010) Effect of micro- and macroporosity of bone tissue three-dimensional-poly(epsilon-caprolactone) scaffold on human mesenchymal stem cells invasion, proliferation, and differentiation in vitro. Tissue Eng Pt A 16: 2661-2673.

Schmeichel KL, Bissell MJ (2003) Modeling tissuespecific signaling and organ function in three dimensions. J Cell Sci 116: 2377-2388.

Shepherd JH, Best SM (2011) Calcium Phosphate Scaffolds for Bone Repair. JOM 63: 83-92.

Shepherd JH, Shepherd DV, Best SM (2012) Substituted hydroxyapatites for bone repair. J Mater Sci-Mater M 23: 2335-2347.
Shibata Y, He LH, Kataoka Y, Miyazaki T, Swain MV (2008) Micromechanical property recovery of human carious dentin achieved with colloidal nano-beta-tricalcium phosphate. J Dent Res 87: 233-237.

Singh H, Ang ES, Lim TT, Hutmacher DW (2007) Flow modeling in a novel non-perfusion conical bioreactor. Biotechnol Bioeng 97: 1291-1299.

Sittichockechaiwut A, Scutt AM, Ryan AJ, Bonewald LF, Reilly GC (2009) Use of rapidly mineralising osteoblasts and short periods of mechanical loading to accelerate matrix maturation in $3 \mathrm{D}$ scaffolds. Bone 44 : 822-829.

Sottile V, Halleux C, Bassilana F, Keller H, Seuwen K (2002) Stem cell characteristics of human trabecular bone-derived cells. Bone 30: 699-704.

Szpalski C, Sagebin F, Barbaro M, Warren SM (2013) The influence of environmental factors on bone tissue engineering. J Biomed Mater Res B Appl Biomater 101: 663-675.

Uemura T, Dong J, Wang Y, Kojima H, Saito T, Iejima D, Kikuchi M, Tanaka J, Tateishi T (2003) Transplantation of cultured bone cells using combinations of scaffolds and culture techniques. Biomaterials 24: 2277-2286.

van Rietbergen BW, H.; Huiskes, R.; Odgaard, A. (1995) A new method to determine trabecular bone elastic properties and loading using micromechanical finiteelement models. J Biomech 28: 69-81.

Volkmer E, Otto S, Polzer H, Saller M, Trappendreher D, Zagar D, Hamisch S, Ziegler G, Wilhelmi A, Mutschler W, Schieker M (2012) Overcoming hypoxia in 3D culture systems for tissue engineering of bone in vitro using an automated, oxygen-triggered feedback loop. J Mater Sci Mater Med 23: 2793-2801.

Vunjak-Novakovic G, Freed LE (1998) Culture of organized cell communities. Adv Drug Deliv Rev 33: 15 30 .

Wang Y, Uemura T, Dong J, Kojima H, Tanaka J, Tateishi T (2003) Application of perfusion culture system improves in vitro and in vivo osteogenesis of bone marrowderived osteoblastic cells in porous ceramic materials. Tissue Eng 9: 1205-1214.

\section{Discussion with Reviewers}

Reviewer I: Was the load applied homogenously or could it only reach certain areas of the scaffold?

Authors: As explained in the section 2.1 the scaffold design and the perfusion strategy (mechanical loading applied perpendicularly to the fluid flow) were defined to uniformly compress the entire scaffold surface. Moreover, the piston and the scaffold surface are both flat with a very low roughness $(\mathrm{Ra}<150 \mathrm{~nm})$ and perfectly parallel. As a result, the load is applied homogeneously on the whole surface of the scaffold. Therefore, the load is transmitted in the whole cubic volume of the scaffold, and as shown by numerical simulations (section 3.1) the strain distribution within the scaffold is a function of its internal porous architecture (Fig. 3B). This porous region, where the cells are seeded, thus presents a gradient of the strain level, 
ranging from $5 \times 10^{-4}$ to $10^{-2}$ (Fig. $3 \mathrm{C}$ ). The highest levels of strains were observed on the struts of the bioceramic scaffolding. No clear correlation between level of the strain and cell fate has been established yet (Fig. 7).

Reviewer I: Does the commitment of the osteoprogenitors correlate with the level of mechanical stimulation in their microenvironment?

Authors: To the best of our knowledge, no study has answered this question yet. In the past, we ourselves analysed the effects of mechanical strain on osteogenic differentiation in vivo, ex vivo (in bone organotypic culture in the Zetos system) and in vitro (David et al., 2007) and showed the osteogenic effect of strain, and especially the enhanced commitment of osteoprogenitor cells to the bone lineage. However, as in many other studies (Mauney et al., 2004) and in the present one, we have not explored a range of mechanical signals and have restricted the analysis (for time and cost efficiency reasons) to a single stimulation condition. Establishing such dose-response effect on osteoprogenitor fate (which will be model dependent and likely "bell shaped") remains to be done. Arguably, our 3D culture model, once optimised might be used to advance this sort of work.

\section{Additional References}

David V, Martin A, Lafage-Proust MH, Malaval L, Peyroche S, Jones DB, Vico L, Guignandon A (2007) Mechanical loading down-regulates peroxisome proliferator-activated receptor gamma in bone marrow stromal cells and favors osteoblastogenesis at the expense of adipogenesis. Endocrinology 148: 2553-2562.

Mauney JR, Sjostorm S, Blumberg J, Horan R, O'Leary JP, Vunjak-Novakovic G, Volloch V, Kaplan DL (2004) Mechanical stimulation promotes osteogenic differentiation of human bone marrow stromal cells on 3 -D partially demineralized bone scaffolds in vitro. Calcif Tissue Int 74: 458-468. 